$[11 \cdot-17 \mathrm{~V}]_{0}$

$$
\begin{aligned}
& \text { أثر الدعم السعري في نمو المحاصيل الستراتيجية في العراق }
\end{aligned}
$$

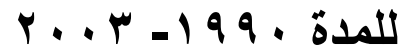

$$
\begin{aligned}
& \text { نسيم زهير حمد }
\end{aligned}
$$

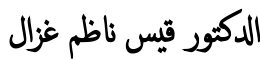

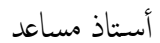

$$
\begin{aligned}
& \text { قسم الاقتصاد الزراعي_كلية الزراعة والغابات }
\end{aligned}
$$

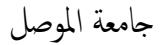

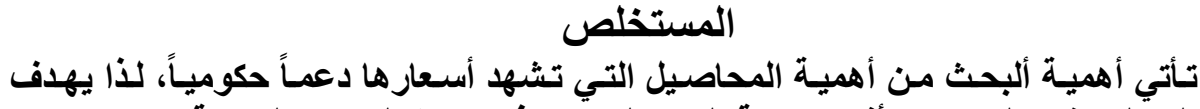

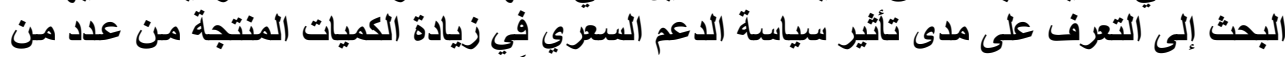

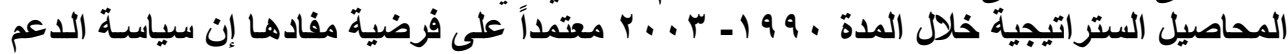

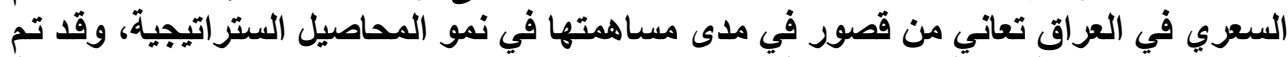

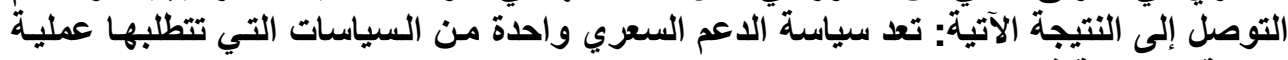
التنمية الزراعية في العراق.

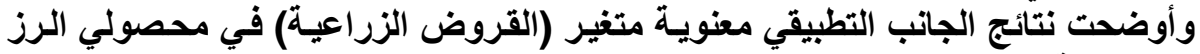

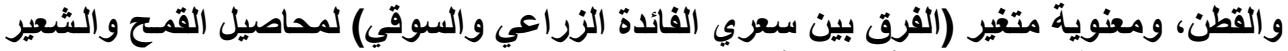

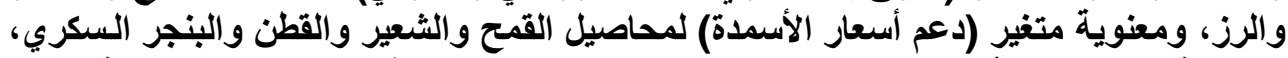

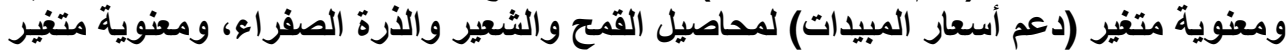

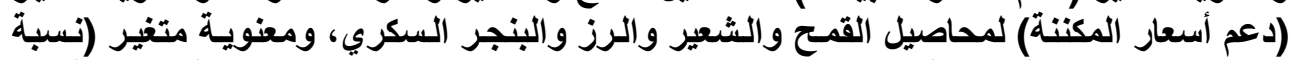

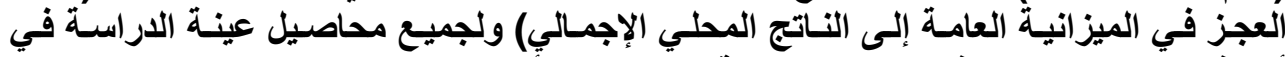

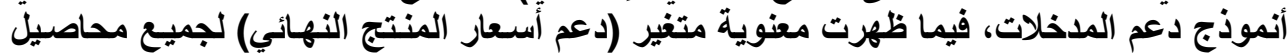

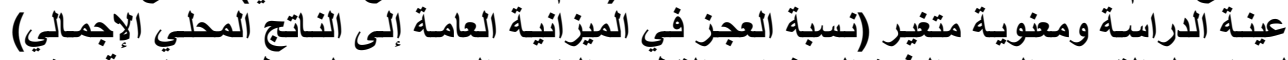

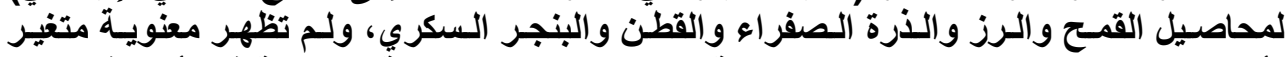

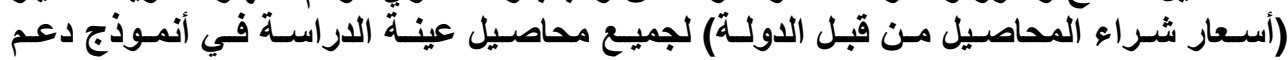

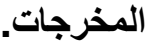




\title{
The Effect of Price Support in the Growth of Strategic Crops in Iraq for the Period 1990- 2003
}

\author{
Kays Nadhim Ghazal (PhD) \\ Assistant Professor \\ Department of Agriculture Economy \\ University of Mosul
}

\author{
Naseem Zuhair Hamad \\ Assistant lecturer \\ Department of Agriculture Economy \\ University of Mosul
}

\begin{abstract}
The importance of the research is emerged from importance of products that their price supported by the government. So, the research aims to know the effect of price support policy in increasing the equinity produced by many strategic crops during the period 19902003. The research depended upon hypotheses that price support policy in Iraq is facing shortage in its connection to growth of strategic crops. The result revealed that: The price support policy is one of the policies required by the agricultural development process in Iraq. The practical side of the research showed that significant variable (agricultural loans) in rice and cotton crops, (the difference between the agricultural and marketing interest rate) in wheat, barley and rice crops, (fertilize support prices) in wheat, barley, rice, cotton and sugar beets, (pesticides price support) in wheat, barley, corn flax crops, (machinery prices support) in wheat, barley, rice and sugar beets, (the budget deficit ratio to the GDP) in all crops studied in input model. Also, the significant value has been revealed in variable (supporting the final product price) in all studied crops, (the budget deficit ratio to the GDP) in wheat, rice, corn flax, cotton and sugar beets. But, there is no significant value for the variable (price of purchased crops by the government) for the all crops studied in output
\end{abstract} model.

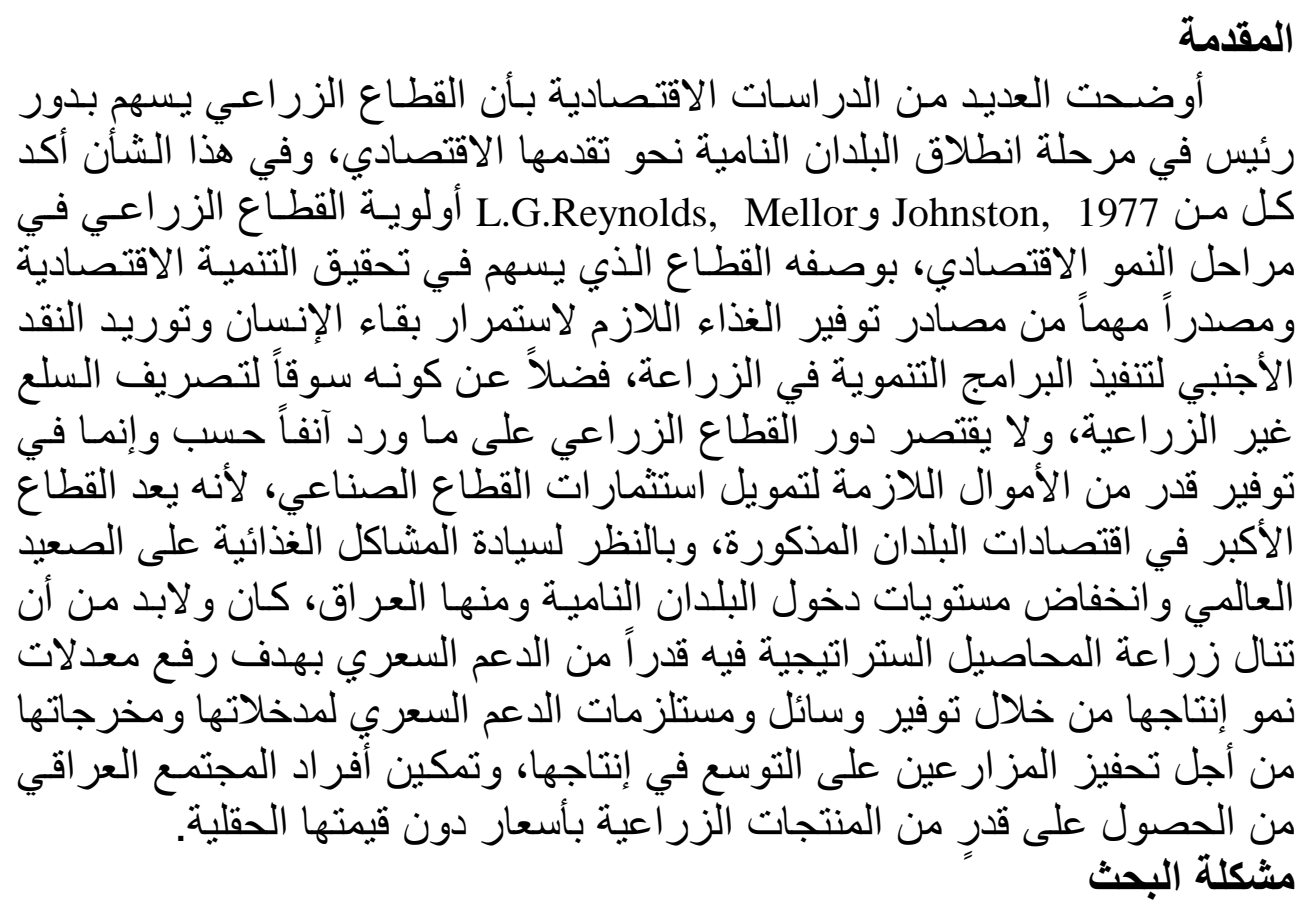




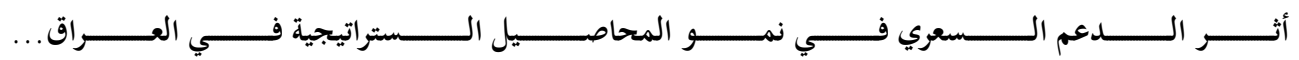

يتسم الطلب المحلي على المحاصيل الستر اتيجية في العر اق بالتز ايد وبمعدلات

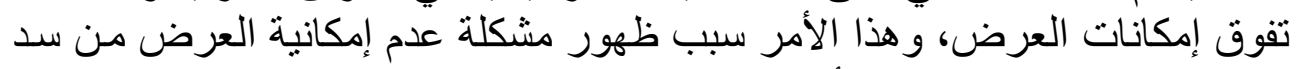

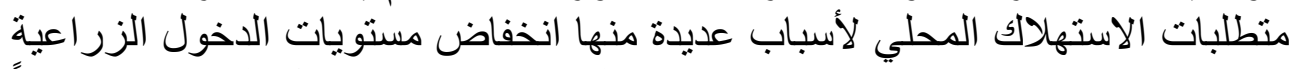

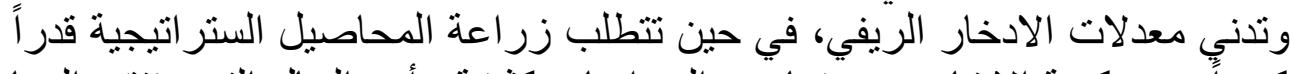

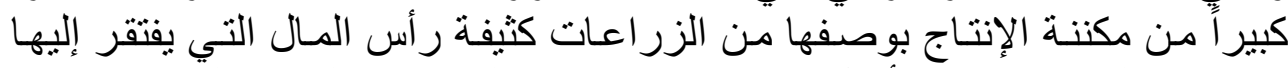

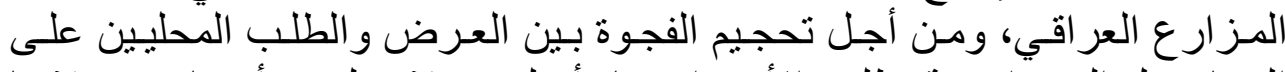

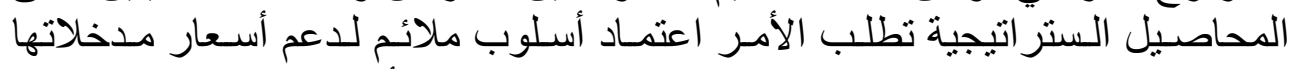

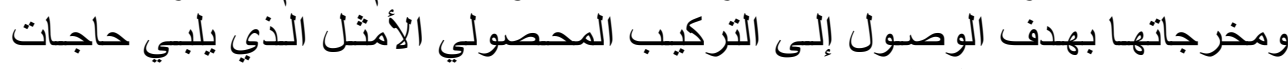
المجتمع من المحاصيل الدذكورة.

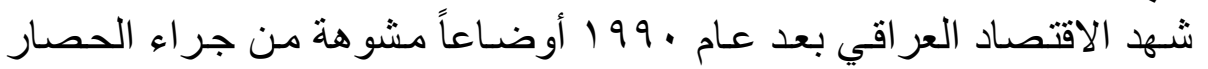
أهمية البحث

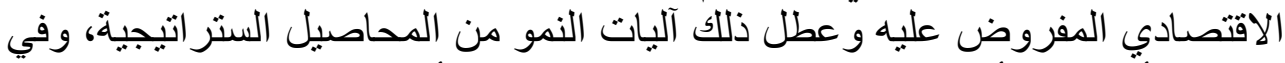

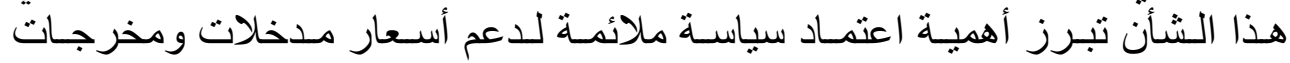

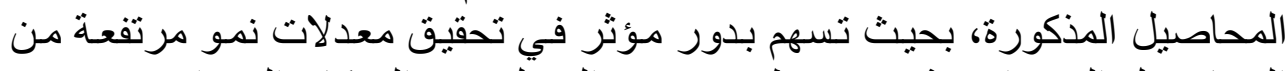

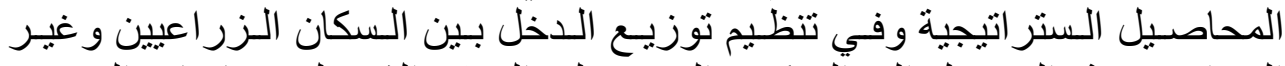

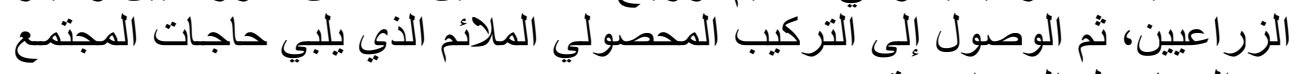

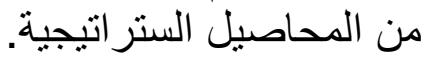

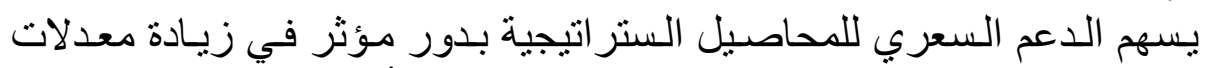
هدف البحث

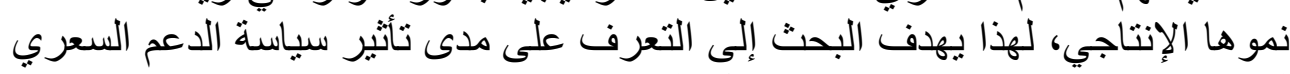

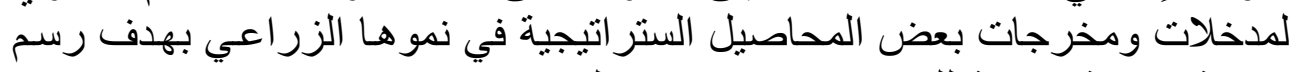
سياسة سعرية ملائمة للتوسع في إنتاجها في العراق.

فرضية البحث

يعتمد البحث على فرضية مفادها أن سياسة الدعم السعري في العراق تعاني

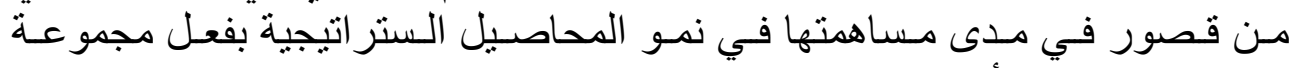

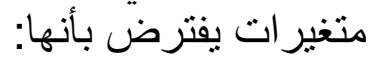
ا ـ متغير ات دعم المدخلات وهي: (القروض الزيا: الزراعية واعية، والفرق بين سعري الفائدة

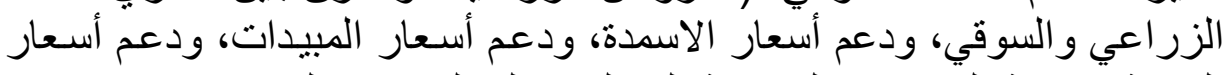

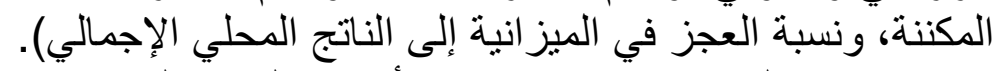

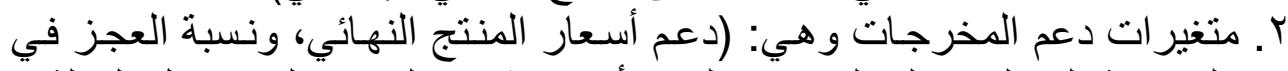
الميزانية إلى الناتج المحلي الإجمالي، وأسعار شراء الدئي المحاصيل من قبل الدولة). 


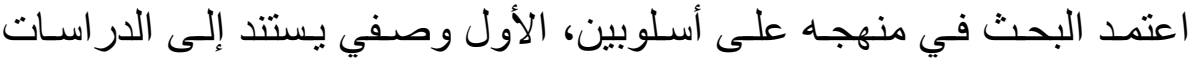

\section{منهج البحث}

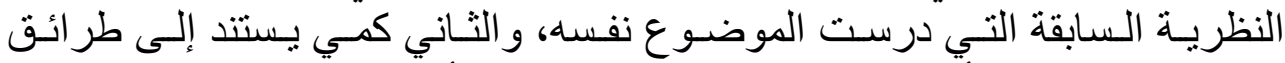

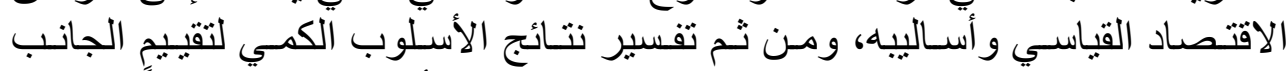

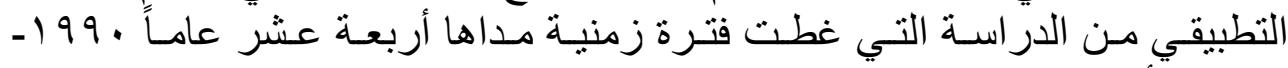

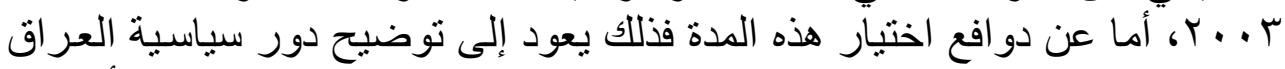

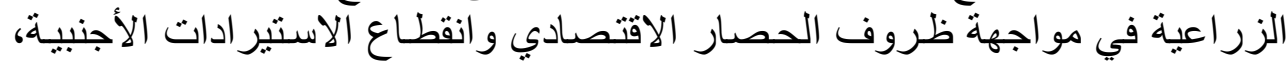

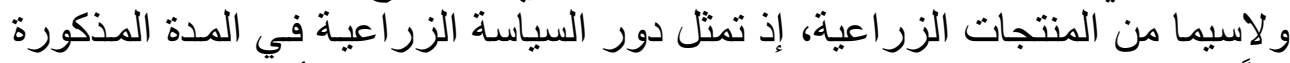

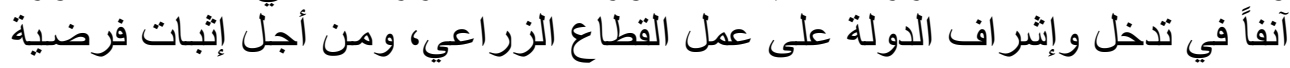

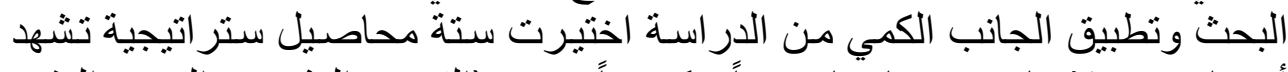

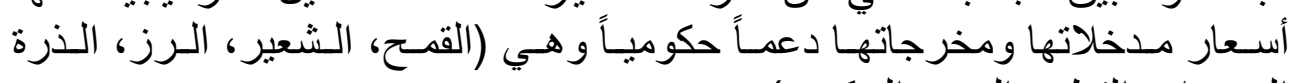
الصفراء، القطن، البنجر السكري).

\section{المنظور التاريخي للاعم السعري للقطاع الزراعي}

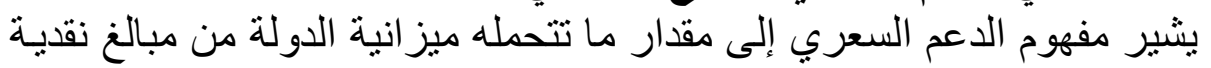

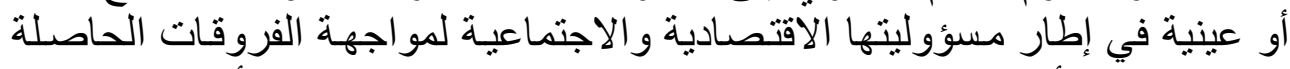

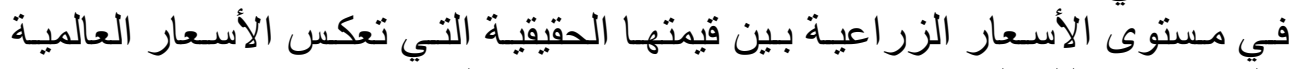

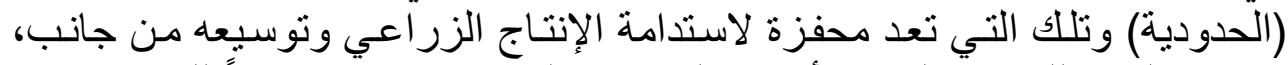

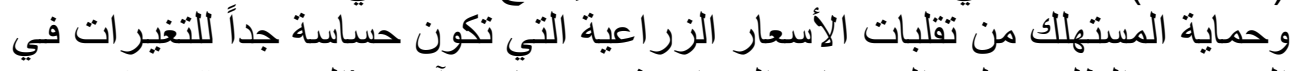

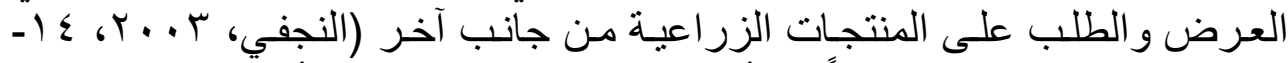

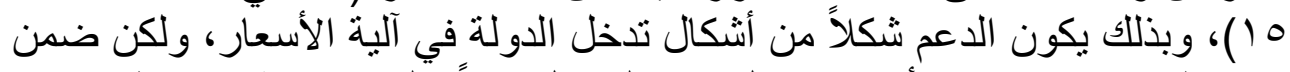

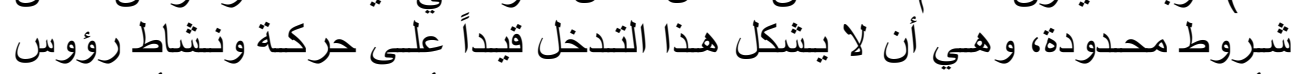

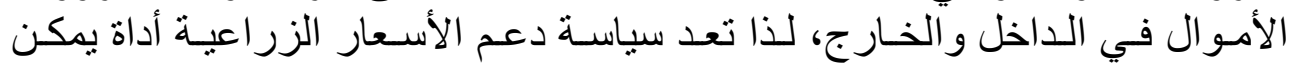

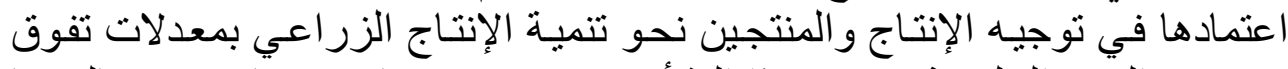

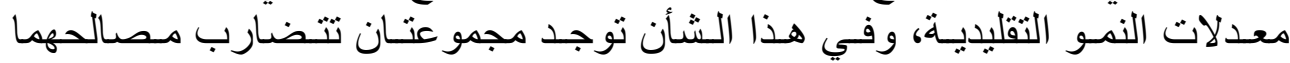

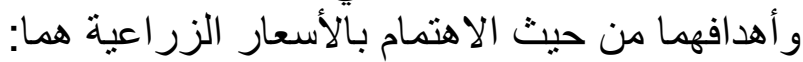

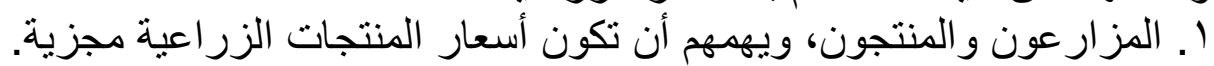

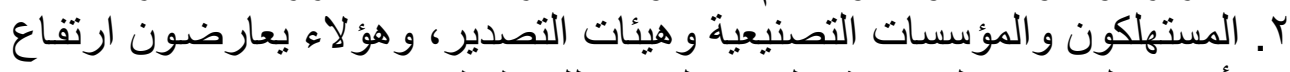

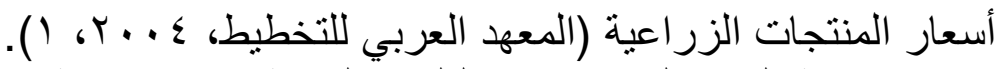

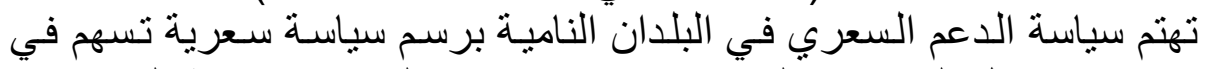

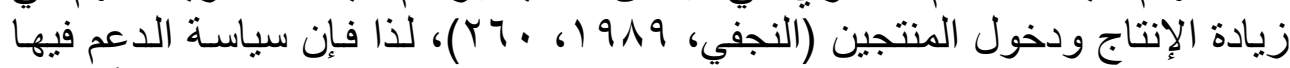

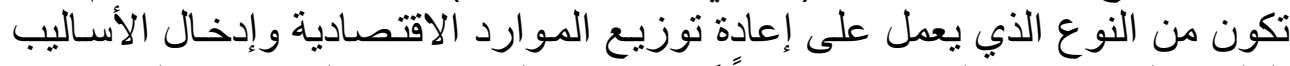

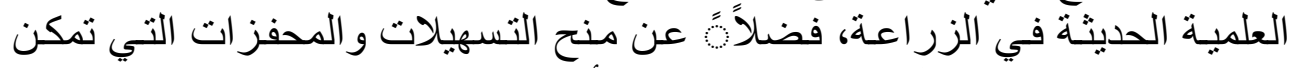

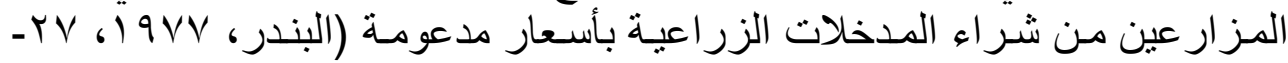

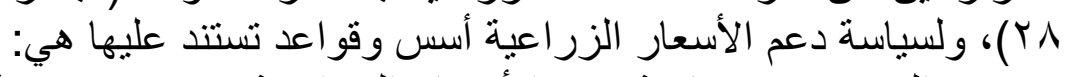

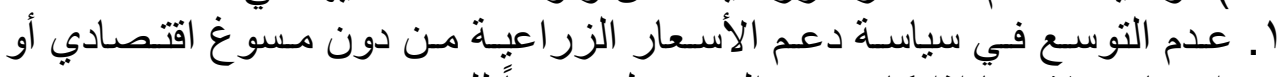
اجتماعي لأسيماً إذا كان سعر المحصول مجزياً للمنتج. 


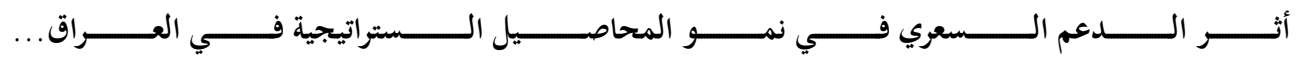

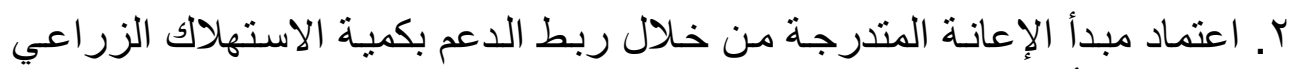

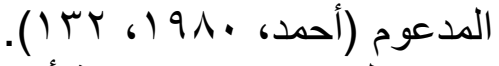

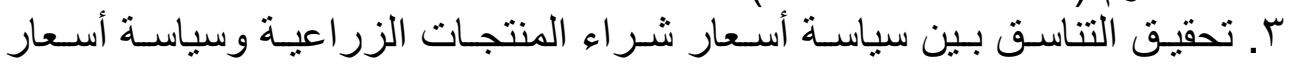

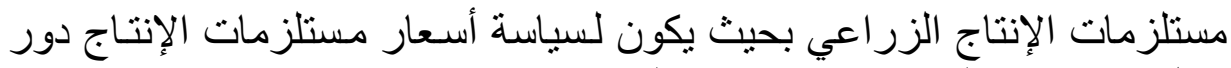

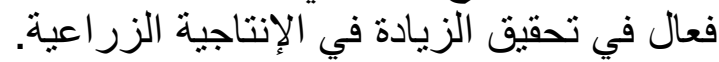

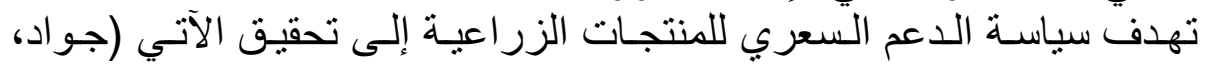
$:(19 Y-19)$ 6) $19 V \mathrm{~V}$ ا ـ تحديد اتجاهـات الإنتـاج الزراعي لتحقيـق أكبر قدر مـن عو ائــ الاستنثمار ات

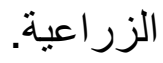

r. إحداث تغييـر في هيكل الإنتاج الزر اعي وفي المساحة المزروعـة والإنتاجيـة

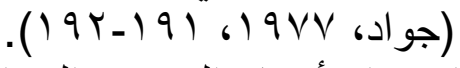

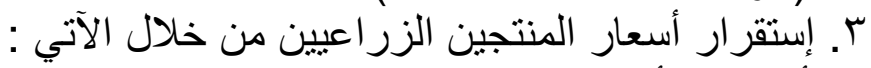

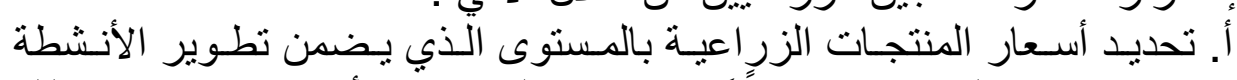

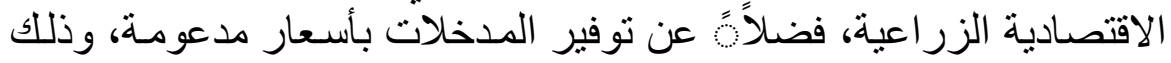

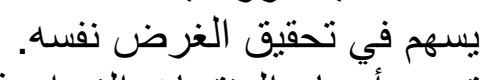

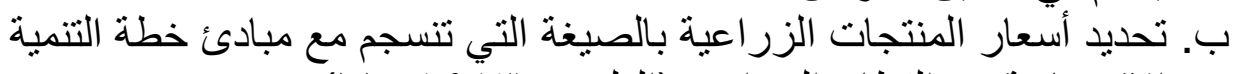

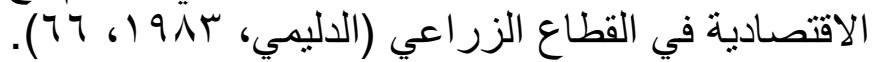

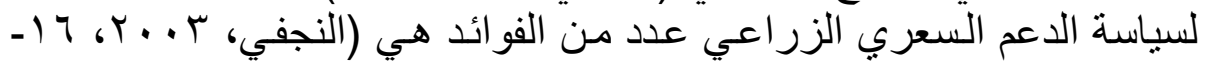
$:(1 \mathrm{~V}$

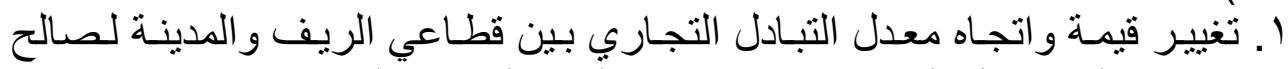

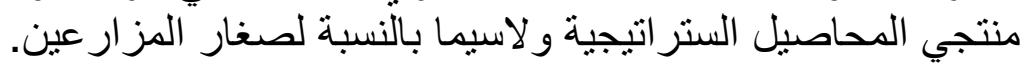

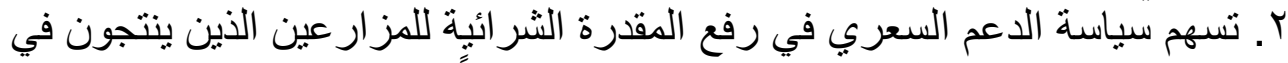

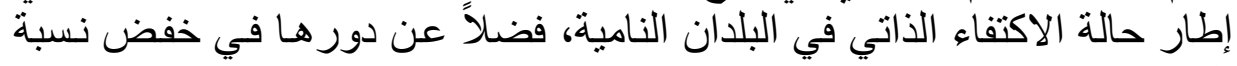
الفقر في المجتمعات الريفية.

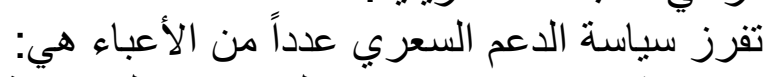

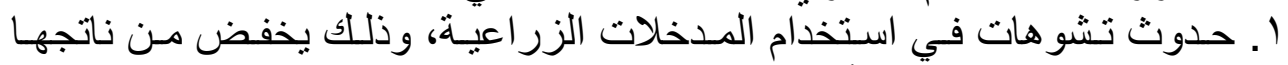
الحدي، ويحمل المجتمع أعباء مادية كبيرة، ويحول دون التون توظيفها في استخدامات

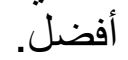

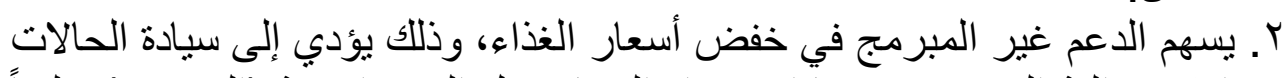

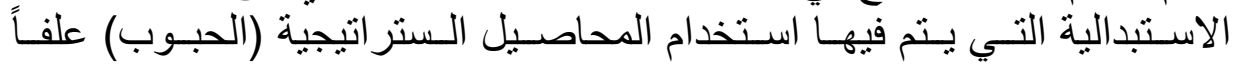

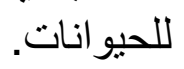
r. يعمل الدعم السعري على زيادة فرص تهريب المحاصيل الستر اتيجية المدعومـة

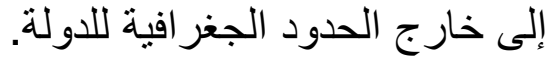

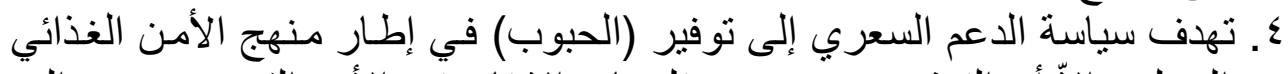

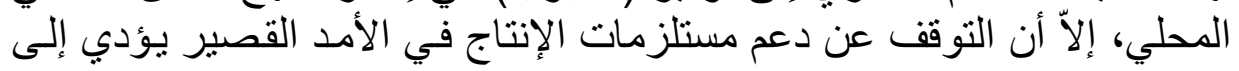


جعل تكاليف الإنتاج أكبر من عوائدها، ويتضح هذا الأمر في المزارع الصنئ الصغيرة

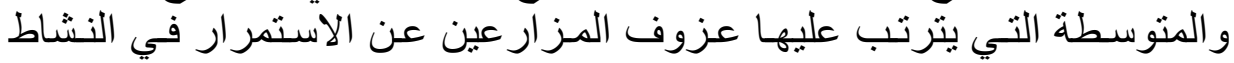
الإنتاجي الزراعي.

العرض المرجعي والاراسـات المعاصرة لأثر الدعم السعري في نمو المحاصيل

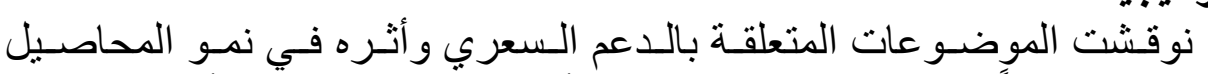
الستراتيجية

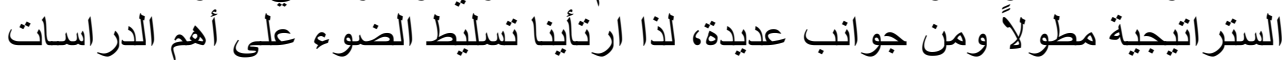

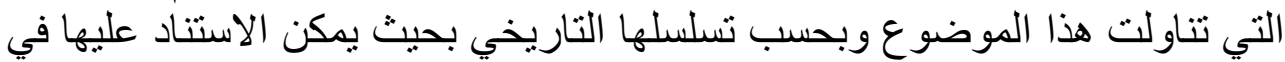
تحليل ومناقشة مشكلة البحث.

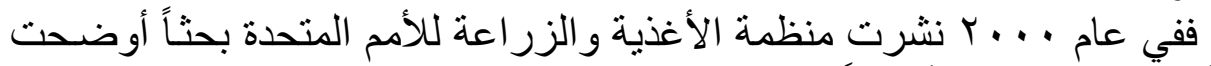

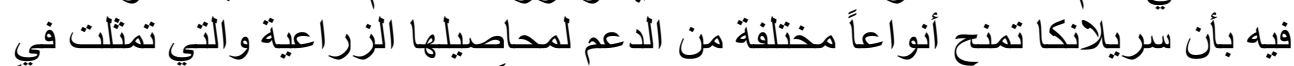

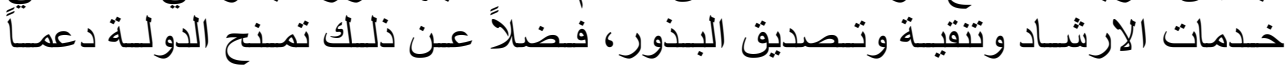

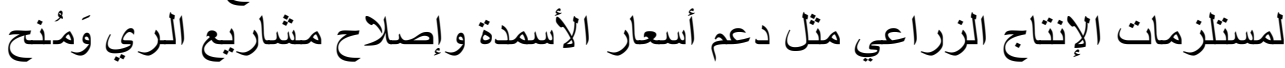

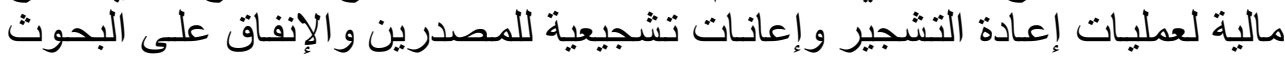

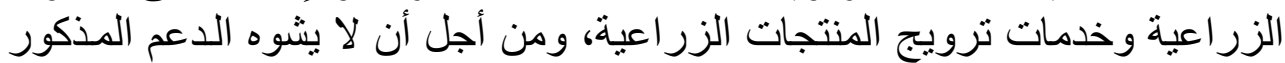

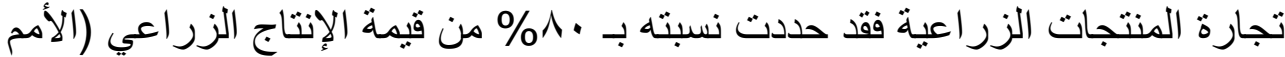

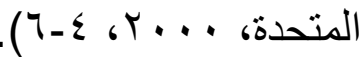

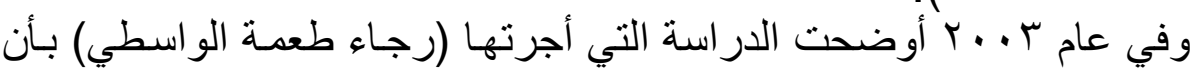

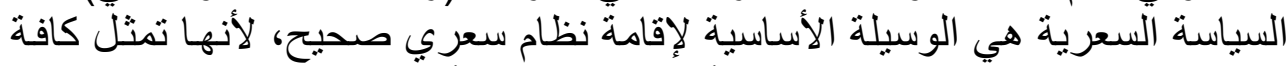

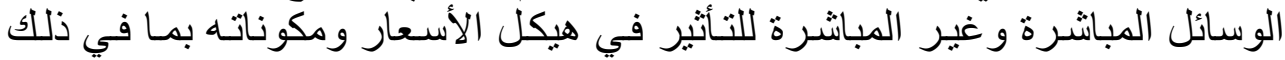

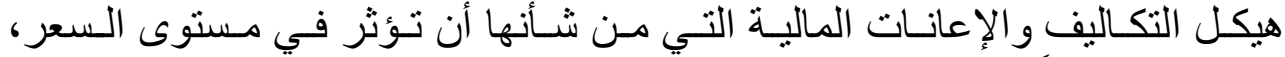

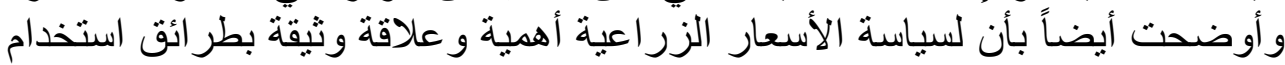

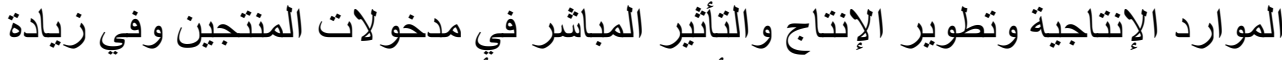

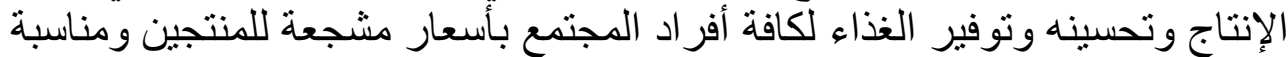

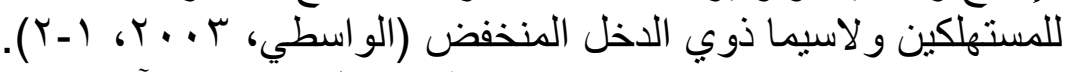

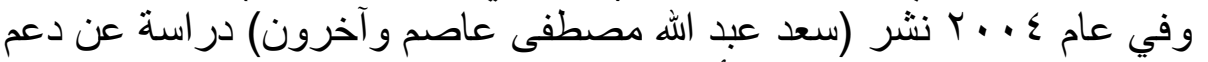

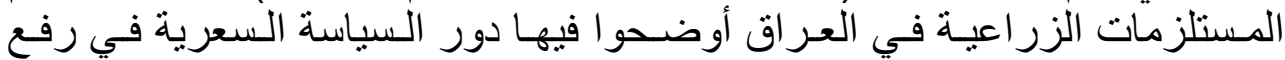

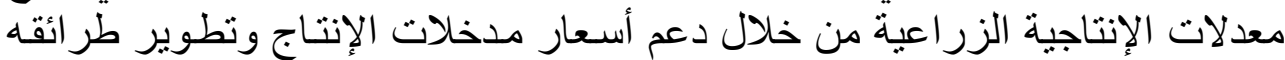

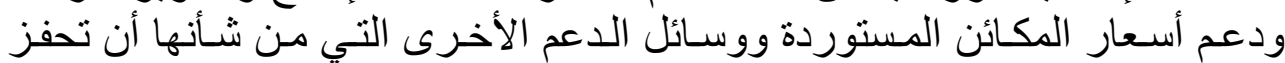

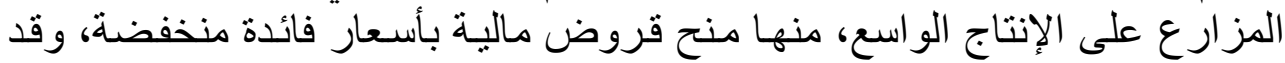

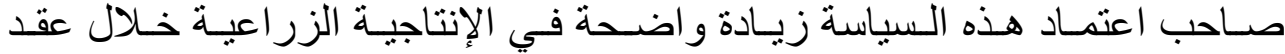

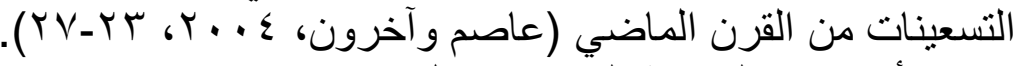

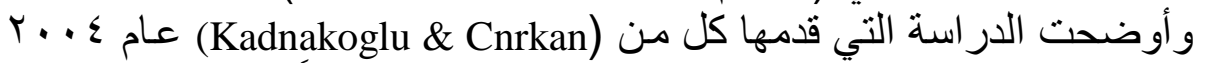

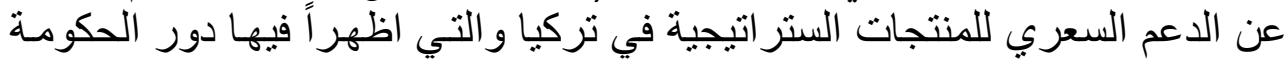

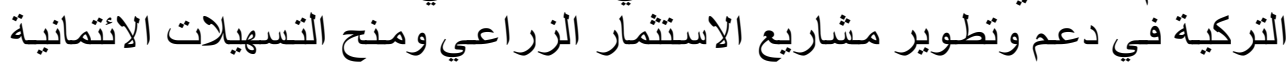
للمزارعين ونطوير المشاريع الإروائية، الأمر الذي ظهر الزير أثره في توسيع المساحات الأنيات 


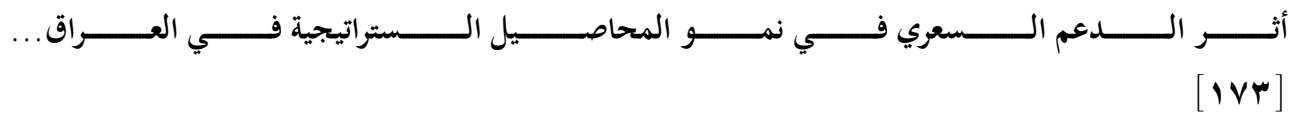

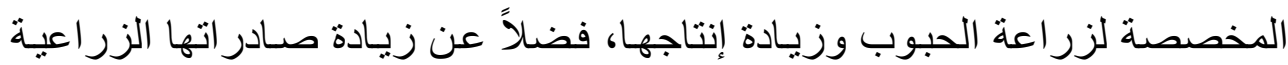

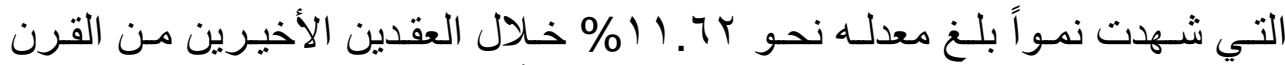

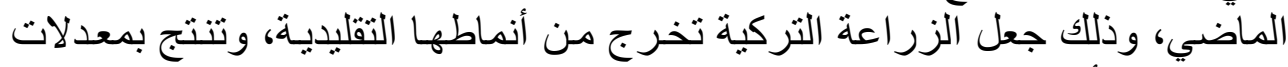

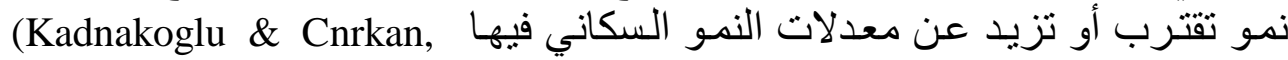
2004, 1)

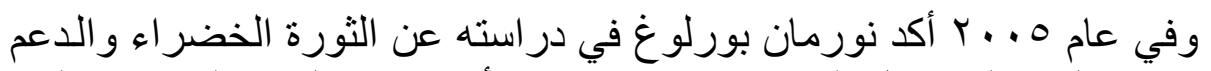

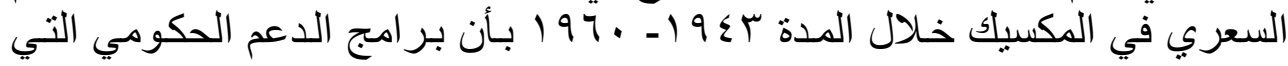

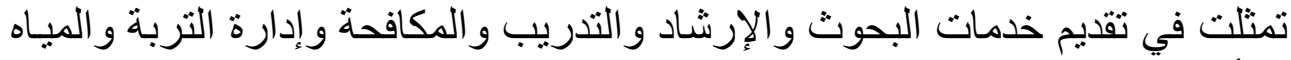

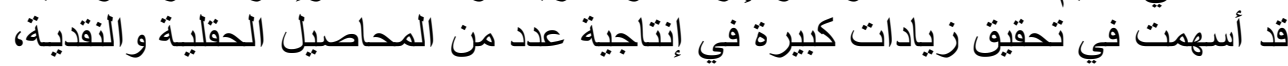

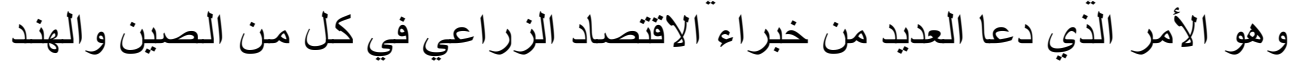

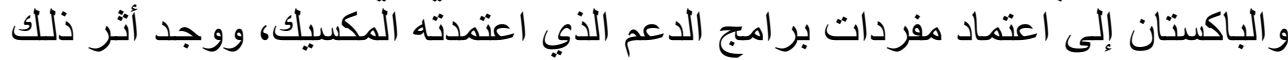

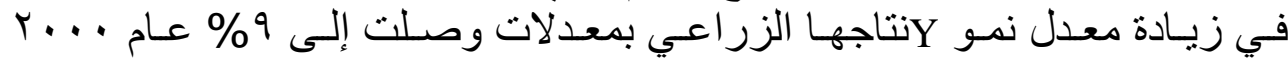

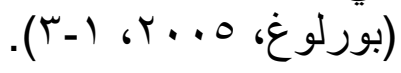

\section{الأنموذج القياسي وتقدير المعلمات وتفسيرها توصيف الأنموذج القياسي المستخدم في التقدير المعات ولفير}

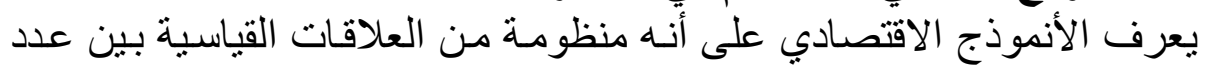

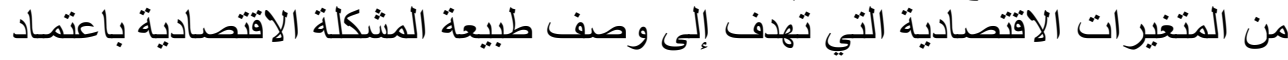

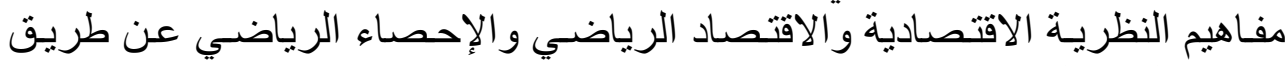

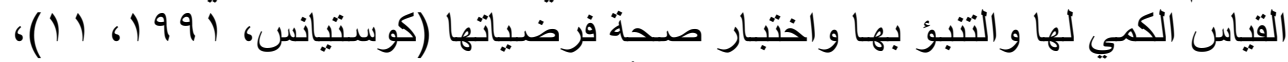

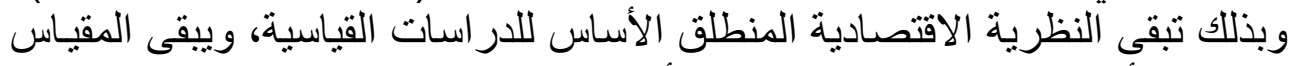

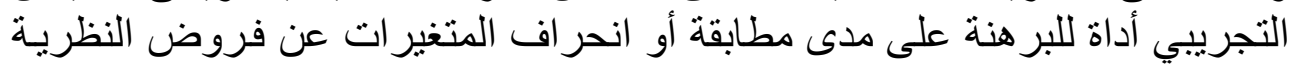

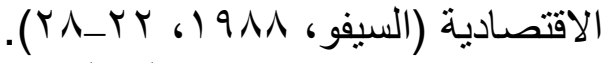

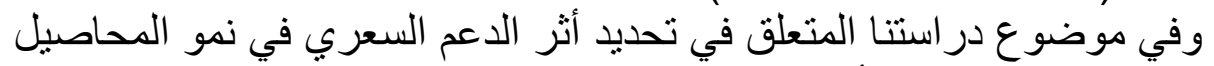

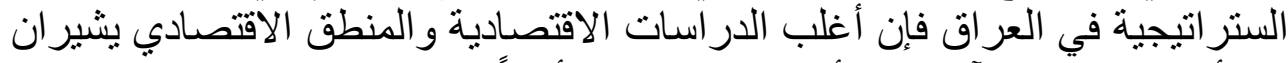

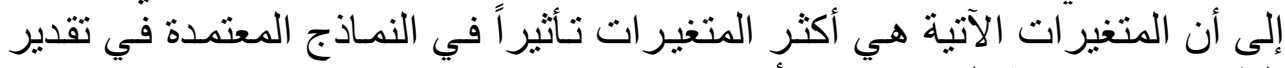

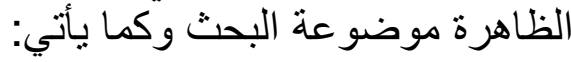

أولاًّ- متغير ات دعم المدخلات

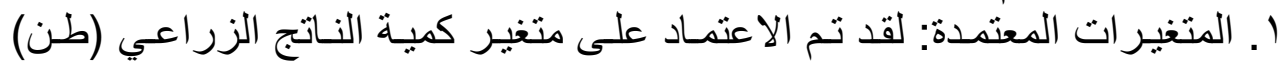

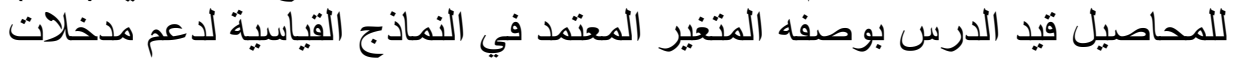

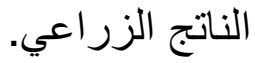
r. المتغير ات المستقلة: لقد تم الاعتماد على المتغيرات الاقتصادية الآتية التي مثلت

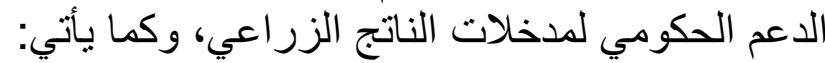
X (ألف دينار ) X

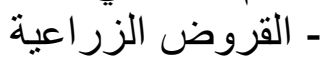
ـ الفرق بين سعر الفائدة الزر اعي وسعر الفائدة السوقي ل 


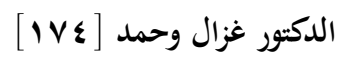

X

_ - دعم أسعار الأسمدة الكيماوية

(الف دينار) X

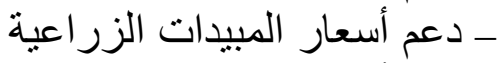

(الف دينار) X $X_{5}$

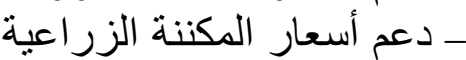

- نسبة العز في الميز انية إلى الناتج المحلي الإجمالي ل نسبة مئوية)

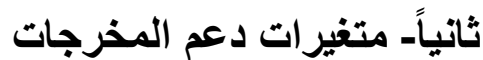

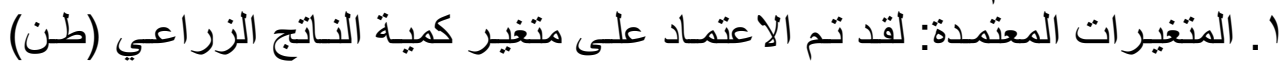

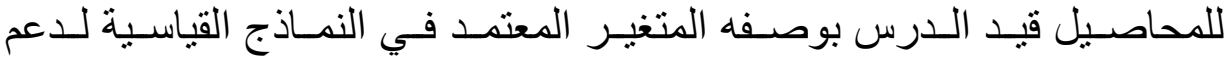

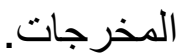

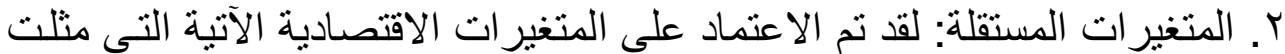

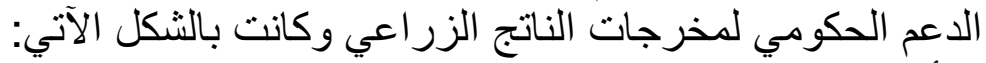
(الف دينار ) X $X_{1}$ - د دعم أسعار المنتج النهائي

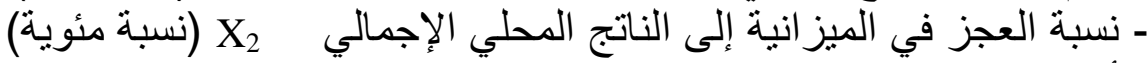
-

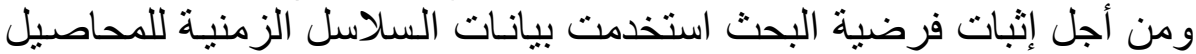

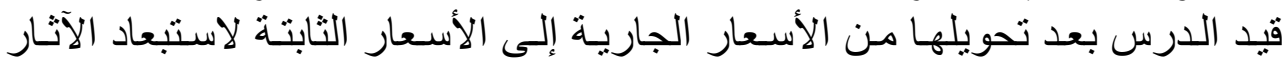

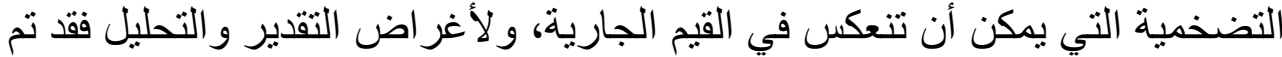

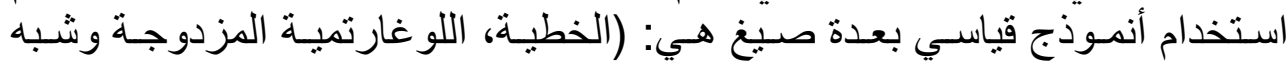

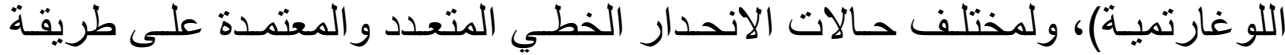

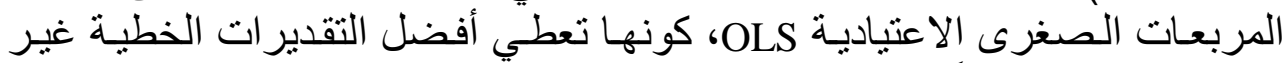

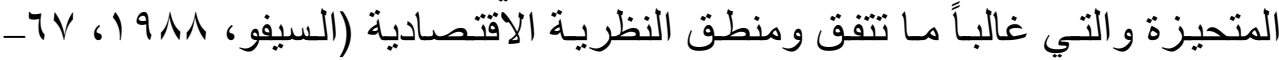

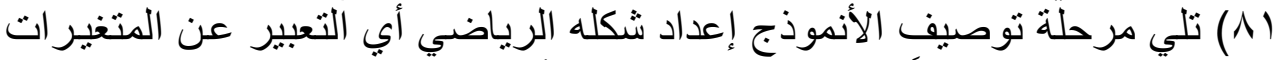

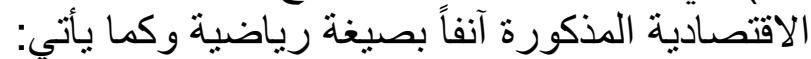

$Y=f\left(X_{1}, X_{2}, X_{3}, X_{4}, X_{5}, X_{6}\right)$

$\mathrm{Y}=\mathrm{f}\left(\mathrm{X}_{1}, \mathrm{X}_{2}, \mathrm{X}_{3}\right)$

وبذلك يمكن صياغة العلاقة الموضحة آنفاً بصيغة نماذج قياسية تأخذ الصورة

$\mathrm{Yi}=\beta_{\mathrm{o}}+\beta_{1} \mathrm{X}_{1}+\beta_{2} \mathrm{X}_{2}+\beta_{3} \mathrm{X}_{3}+\beta_{4} \mathrm{X}_{4}+\beta_{5} \mathrm{X}_{5}+\beta_{6} \mathrm{X}_{6}+\mathrm{ui}$

$\mathrm{Yi}=\beta_{\mathrm{o}+} \beta_{1} \mathrm{X}_{1}+\beta_{2} \mathrm{X}_{2}+\beta_{3} \mathrm{X}_{3}+\mathrm{ui}$

نتائج التحليل القياسي لأثر الدعم السعري في نمـو المحاصيل الستراتيجية في

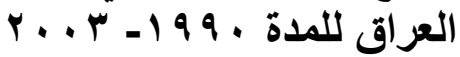

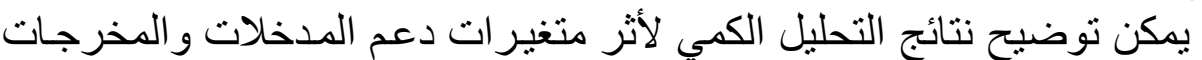

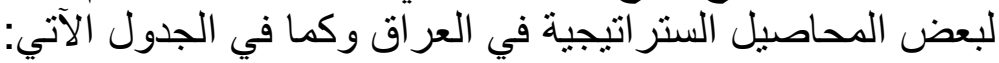




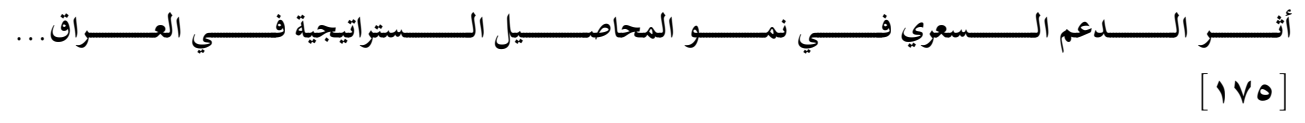

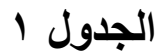

نتائج التحليل الكمي لأنموذجي دعم المدخلات والمخرجات للمحاصيل الزراعية التي

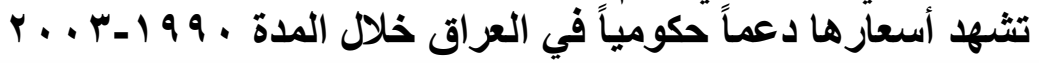

\begin{tabular}{|c|c|c|c|c|c|c|c|c|c|c|c|c|}
\hline \multirow{4}{*}{ 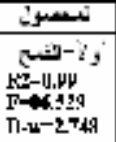 } & \multicolumn{7}{|c|}{ 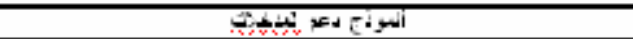 } & لسعبوز & \multicolumn{4}{|c|}{ 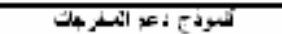 } \\
\hline & $\overline{7}$ & YI & $x^{2}$ & Y3 & $x 4$ & $\mathrm{x}^{5}$ & 3 & \multirow{3}{*}{ 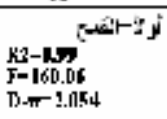 } & zi & II & $x^{2}$ & .5 \\
\hline & Di & impir & $c: n$ & 0.1 .77 & 3.7 .1 & C II: & . .1 .8$. & & $\mathrm{Di}_{\mathrm{i}}$ & 1.574 & P & ..:.: \\
\hline & $t^{-}$ & impir & 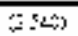 & (2.4.3) & $3856 !$ & $3(05)$ & (3. & & $\mathbf{1}^{+}$ & (2) & 4.795 & m: \\
\hline \multirow{3}{*}{ 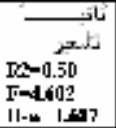 } & $\mathrm{XI}$ & ता & 32 & $x$ & $\mathrm{K4}$ & $3 x^{2}$ & $\mathrm{x}$ & \multirow{3}{*}{ 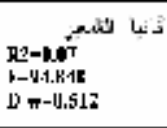 } & $3 \times 1$ & $\mathrm{x}$ & $5 x^{2}$ & $\mathrm{xi}$ \\
\hline & DI & $w_{\mu}^{\prime \prime}$ & $x \mathrm{cc}_{2}$ & 0.035 & $500 \mathrm{c}$ & $\operatorname{coc} 3$ & 8.75 & & Did & $3 \% 9$ & $m^{\prime} w_{\mu^{\prime}}^{\prime}$ & :.:.: \\
\hline & L & $m_{m} \cdot r$ & $\approx(b-1)$ & a.s: & $\because-4$ & $\therefore: 3$ & $32 s ?$ & & $\mathbf{i}^{+}$ & $3(x)$ & $m^{\prime} w_{m}$ & $m ;$ \\
\hline \multirow{3}{*}{ 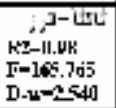 } & $\mathbf{n T}$ & ता & 82 & xis & $\mathrm{X} 4$ & $5 \mathrm{x}^{2}$ & $\mathbf{x o}$ & \multirow{3}{*}{ 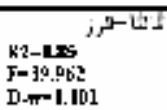 } & xy & $\mathrm{x1}$ & 32 & $x$ \\
\hline & EI & $\mathrm{CL2}$ & $-3 A:=$ & 0.237 & wimpin & C & $00 \% t$ & & BA & 0.324 & $-c o s ?$ & :":!" \\
\hline & $\mathrm{l}^{*}$ & $a \leqslant 3$ & 3.8 & $(1.923 \%$ & my...: & $(33)$ & $3 . .13$ & & $a^{4}$ & $\approx($ a) & $0.21 \%$ & $\overline{m i} ;$ \\
\hline \multirow{3}{*}{ 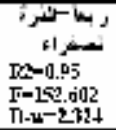 } & Y & Y1 & xth & $\mathbf{Y I}$ & $\mathrm{xt}$ & $x^{2}$ & $x$ & \multirow{3}{*}{ ربتراء } & 조 & $\mathrm{xI}$ & $\mathrm{xt}^{2}$ & $\bar{S}$ \\
\hline & DI & ("):"in & (mo:.:'v & ג:":m:"." & 3.: $7:$ & 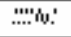 & $.0 . \$ 3$ & & Did & 0.505 & $-c .452$ & $m . \%$ \\
\hline & t- & $m_{\mu}{ }^{\prime 2}$ & e:":m! & $\mathrm{m}_{\mathrm{m} \boldsymbol{}}$ & $i s \cdot \%$ & 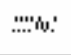 &.$\leqslant 1 \% \pi$ & & a & (: & ox & $m . y$ \\
\hline \multirow{3}{*}{ 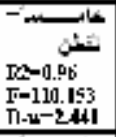 } & $\begin{array}{l}\mathbf{X I} \\
\end{array}$ & 21 & $\mathrm{sz}$ & 2.1 & $x_{4}$ & 可 & $\mathbf{x} \mathbf{n}$ & \multirow{3}{*}{ 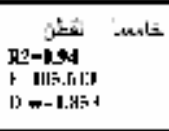 } & :y & $\mathrm{xi}$ & $\mathrm{xz}$ & $x^{4}$ \\
\hline & DT & tot & Thi...." & $0.27 \%$ & 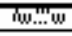 & ow... & T.189 & & DI & 3.28 & -2450 & ?!.: \\
\hline & t- & $(2 \leq 2)$ & 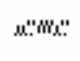 & $2=4 \%$ & (w).:.'w & w...". & , 275 & & 1 & $\because 3$ & זֶר & w.": \\
\hline \multirow{3}{*}{ 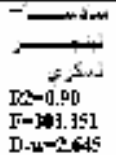 } & y & प1 & st & $\mathbf{Y}$ & $x 4$ & $\mathrm{R}^{4}$ & $x$ & \multirow{3}{*}{ 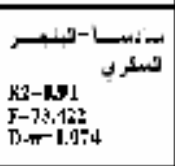 } & 제 & $x I$ & 35 & $\overline{X S}$ \\
\hline & $\mathrm{Hi}$ & 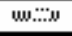 & $\mu=m_{\lambda}:$ & $\mid 114\}$ & nw:::ww & 111112 & - $150+13$ & & $\mathrm{Ki}$ & $115 !$ & $-113 !$ & im: \\
\hline & L & w:... & $m=m_{L}$ & $0.52 \%$ & $m_{\text {w }}$ & $\therefore: 97$ & $0.0 \%$ & & $1^{4}$ & $\therefore \equiv(3)$ & $(E .20 \%$ & $m ;$ \\
\hline
\end{tabular}

المصدر: من إعداد الباحثان بالاعتماد على النتائج القياسية للمحاصيل الزر اعية قيد الدرس.

إذ إن متغير ات دعم المدخلات هي:X

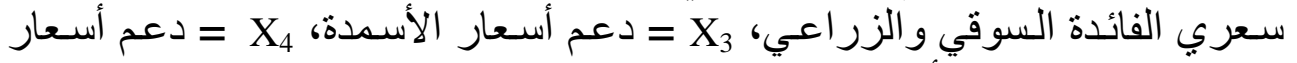
المبيدات، X X ألما متغير آت دعم المخرجات هي:X العجز في الميز انية إلى النـاتج المحلي الاجمـالي، XX قبل الدولة.

\section{ا 1 ـ نتائسج دعم المدخلات}

تشير نتائج الجدول الموضح آنفاً إلى معنويـة متغير (القروض الزئل

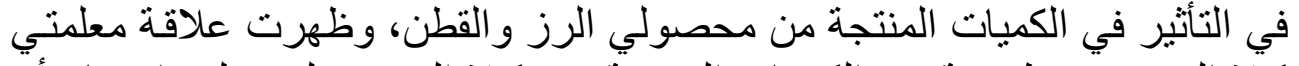

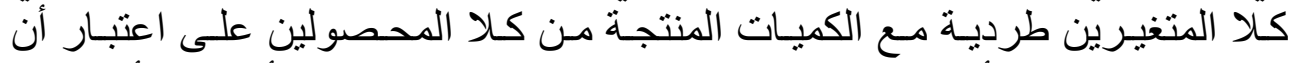

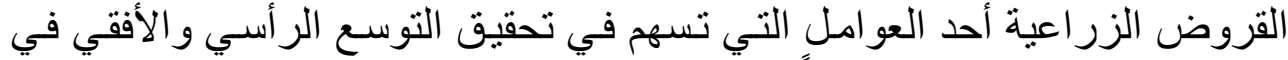

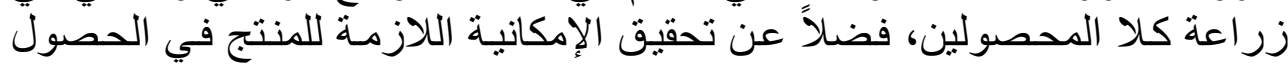
على التجهيز ات الزراعيـة لإنتاج المحاصيل فيد الدرس وتطوير طرائق إنتاجها 


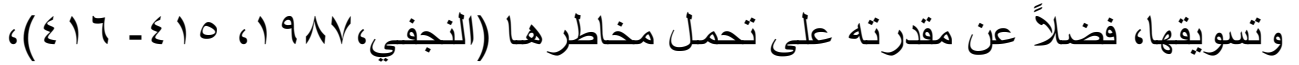

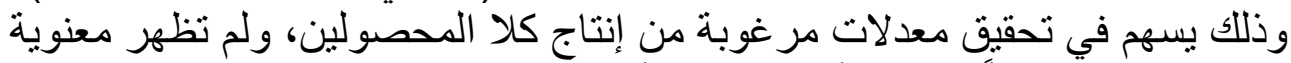
المتغير المذكور آنفاً في بقية ألدحاصيل الأخرى.

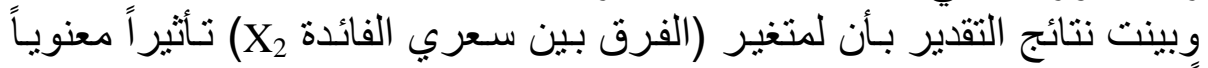

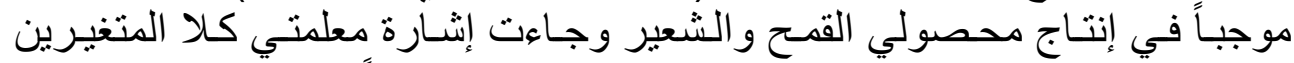

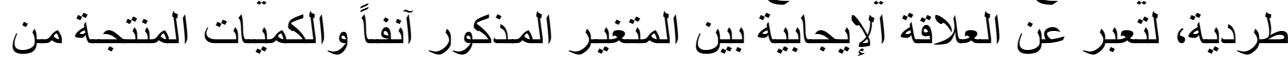

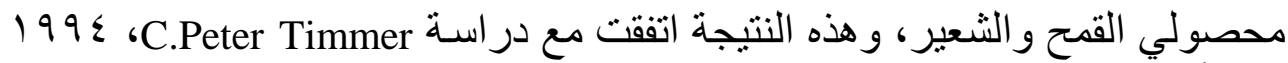

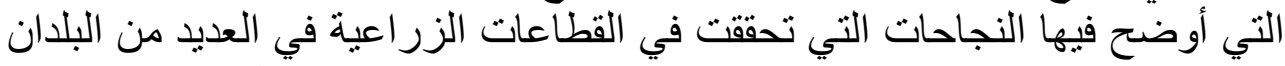

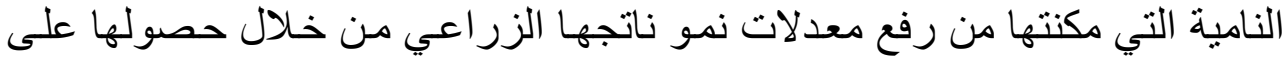

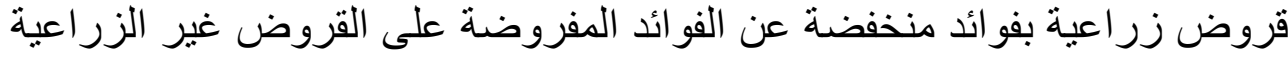

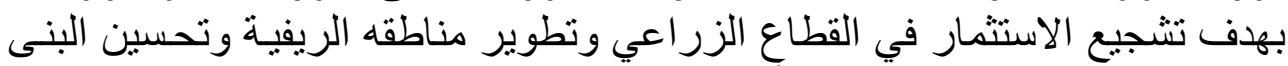

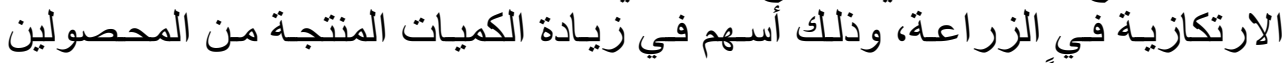

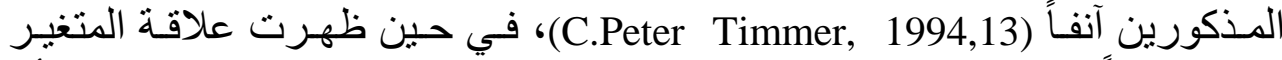

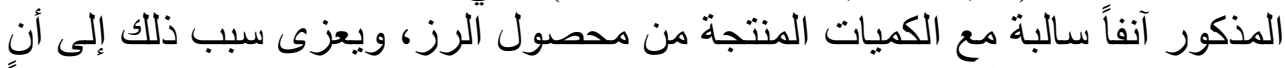

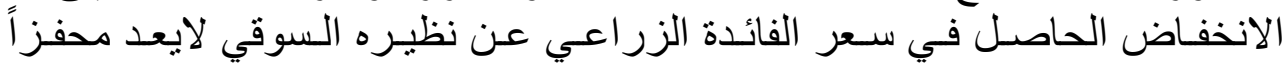

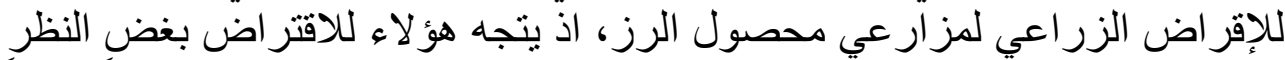

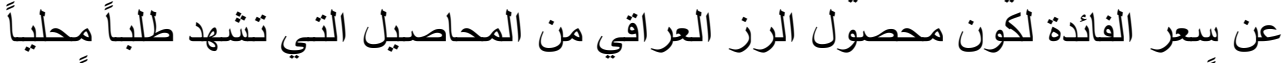

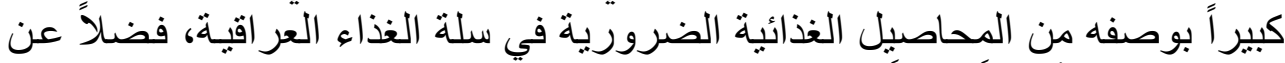

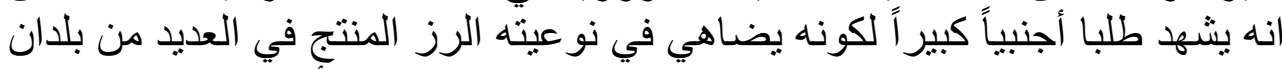

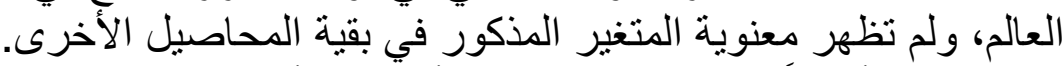

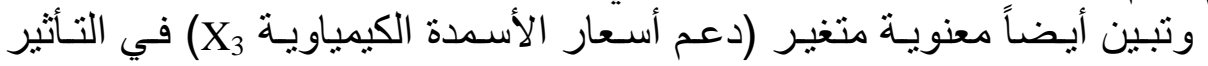

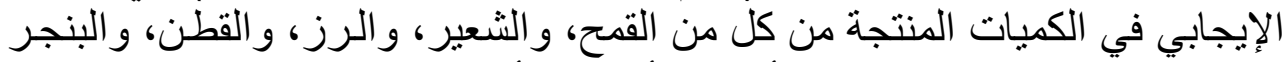

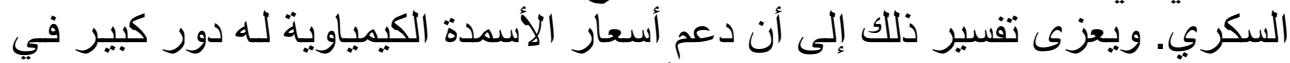

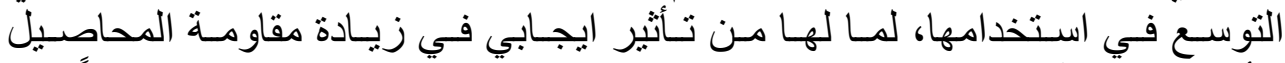

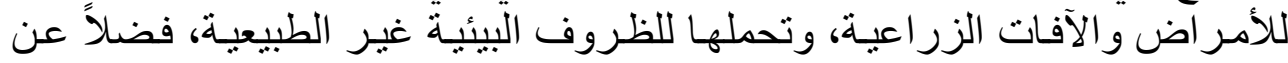

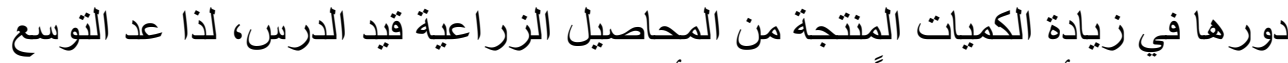

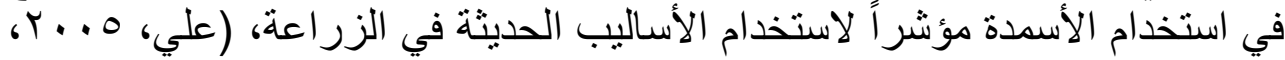

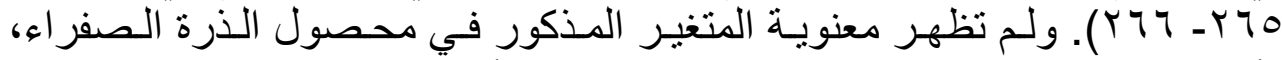

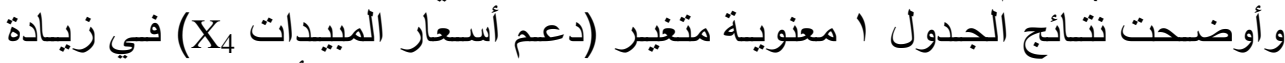

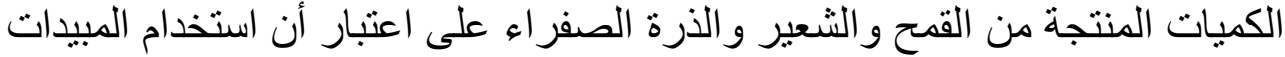

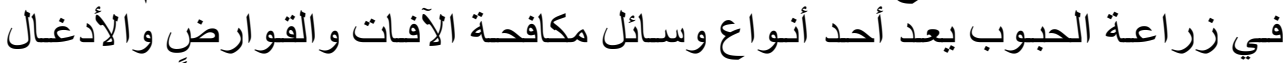

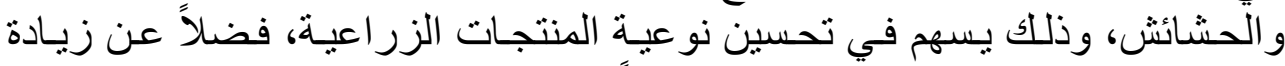

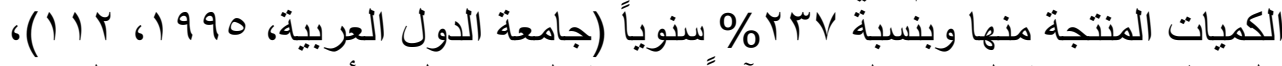

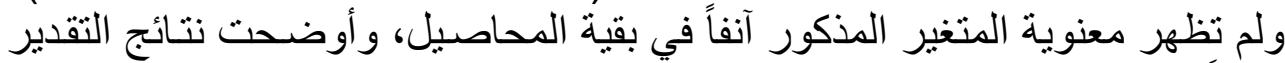

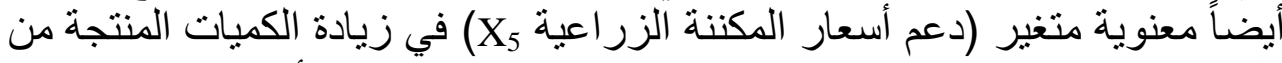

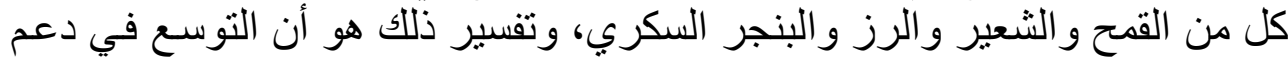
أسعار المكننة الزر اعية يعد من العو امل المهمة التي تسهم في إمكانية التغلب على لئى 


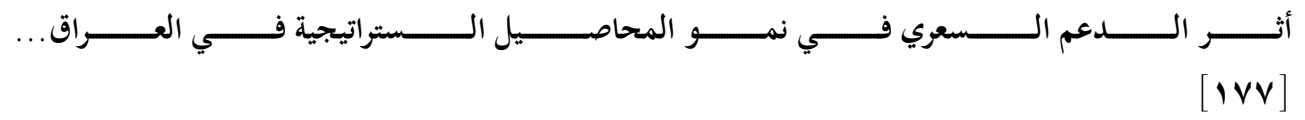

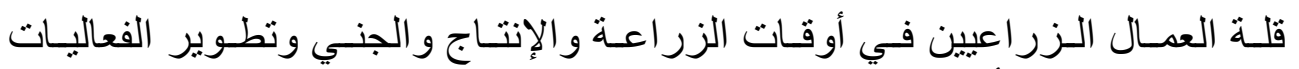

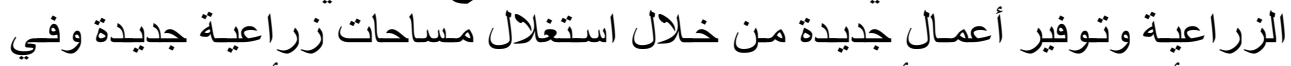

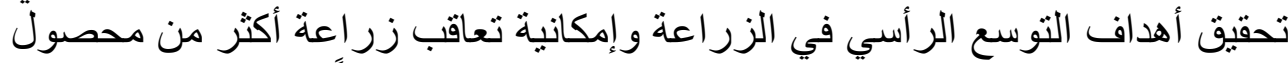

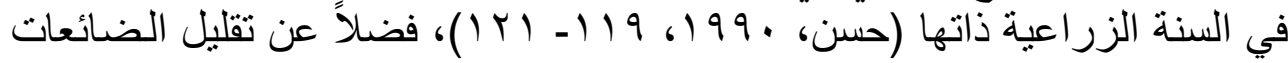

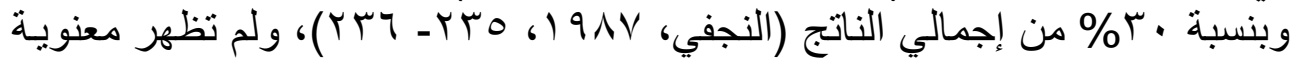

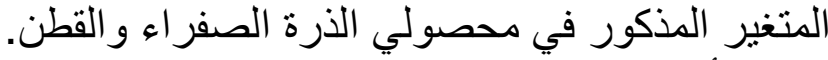

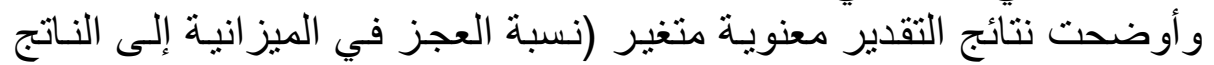

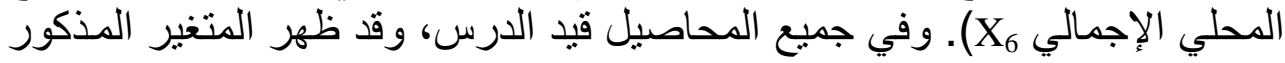

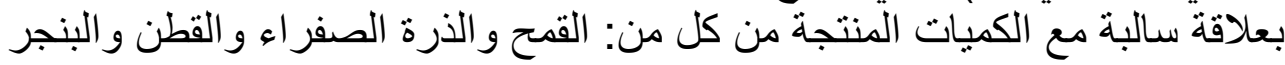

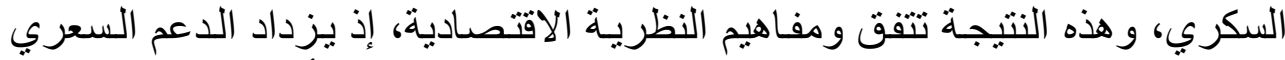

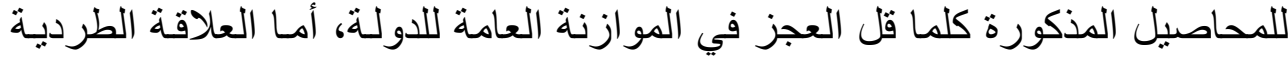

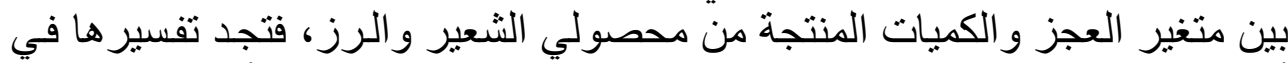

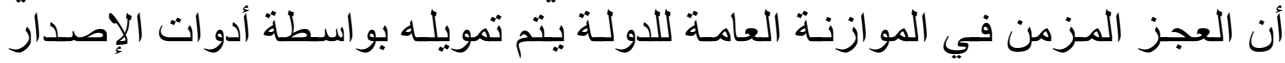

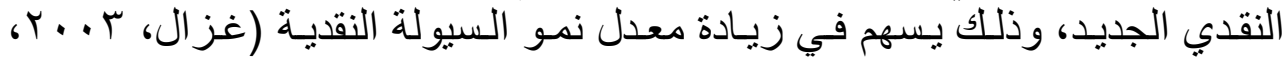

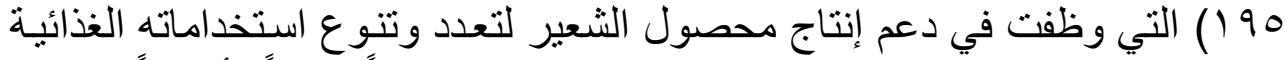

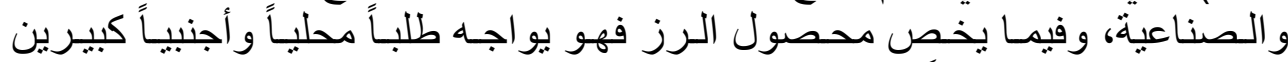

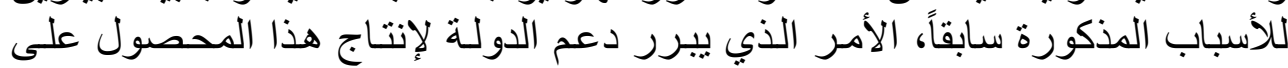

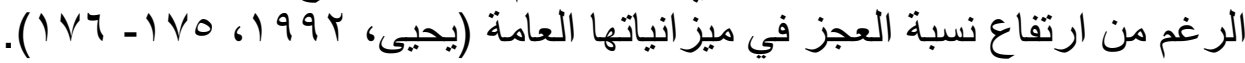

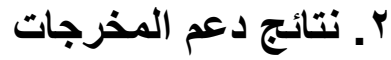

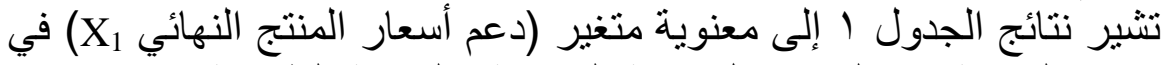

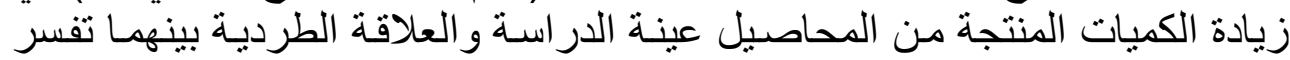

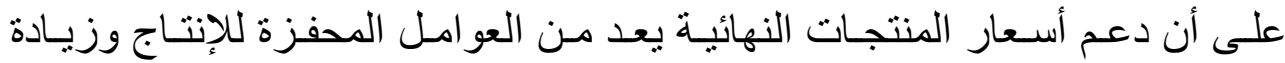

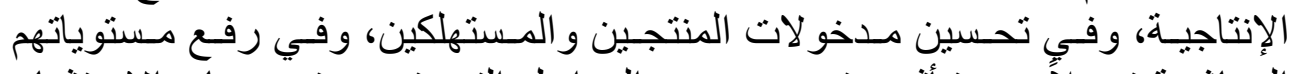

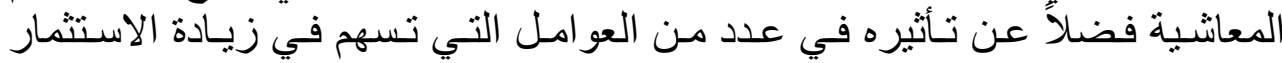

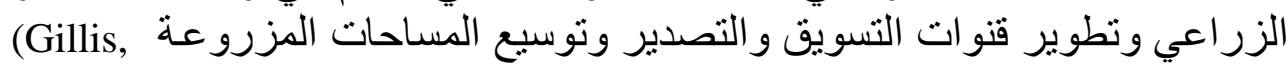
.1987, 469-512)

وبينت نتائج الجدول معنوية (نسبة العجز في الميز انية العامة إلى الناتج المحلي

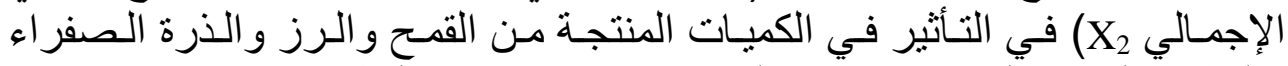

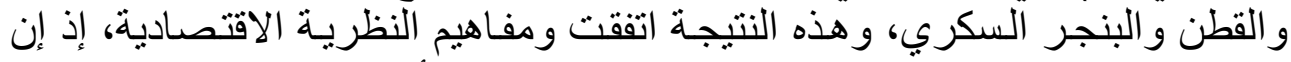

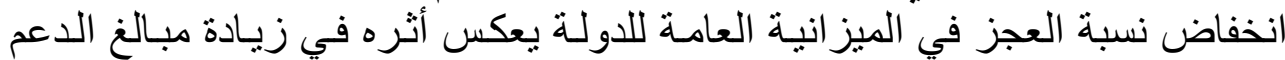

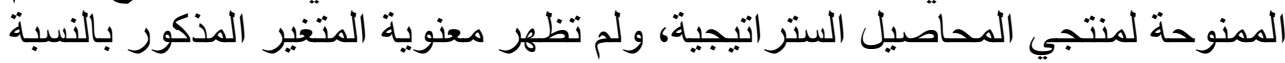

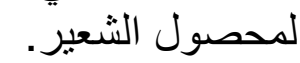

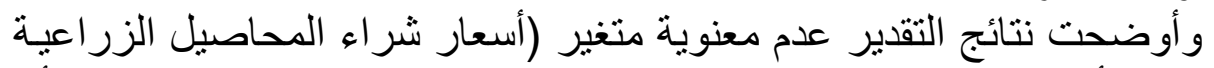

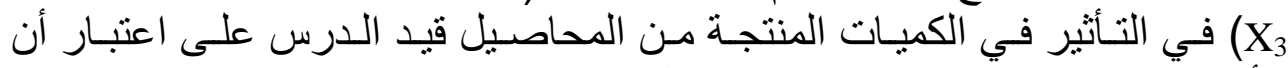
الأسعار التي تشتري بها الدولة المحاصيل المذكورة من المنتجين لم تكن مجزية اللى الى الى الثياري 


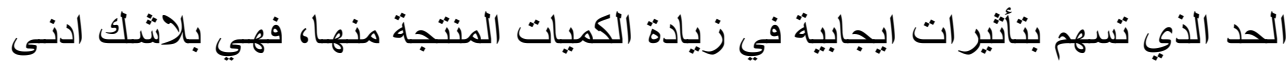

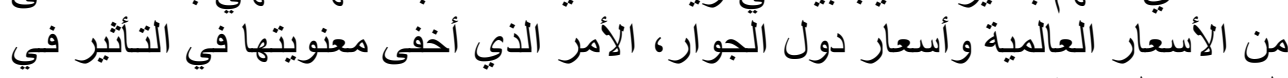

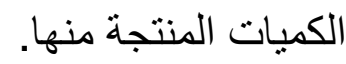

\section{الاستتتاجات والتوصيات}

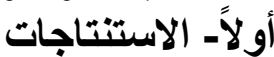

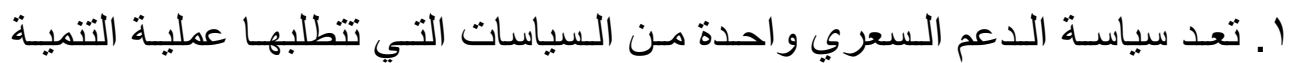

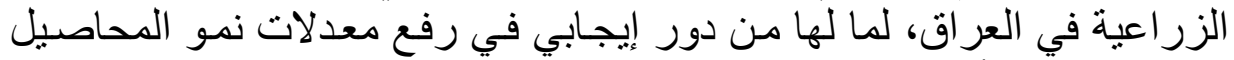

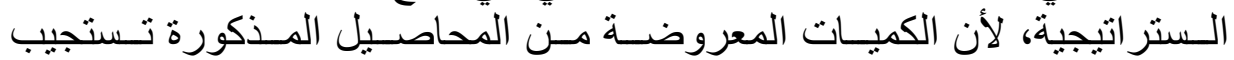

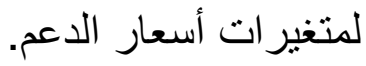

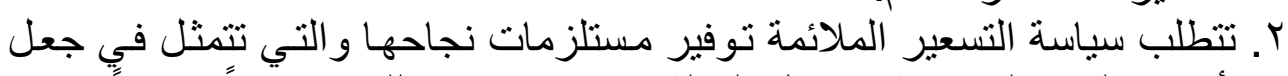

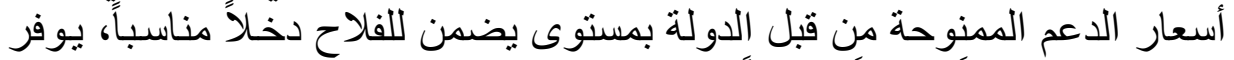

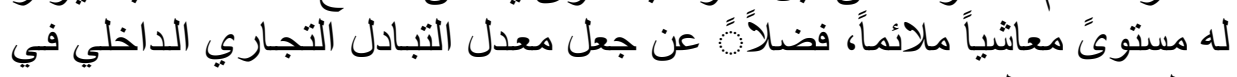

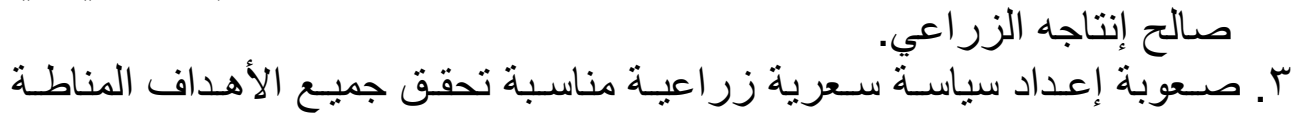

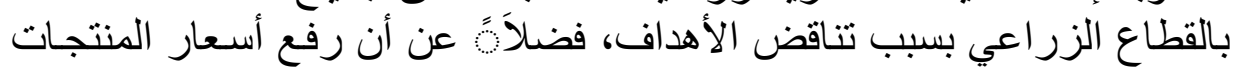

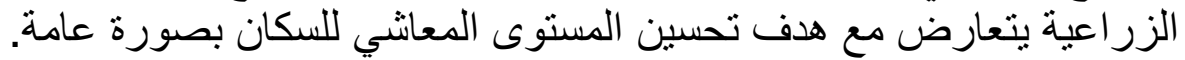

\section{ثانياً التوصيات}

1. التنسيق بين السياسة السعرية الزر اعية والسياسات الأخرى المؤثرة في الإنتاج

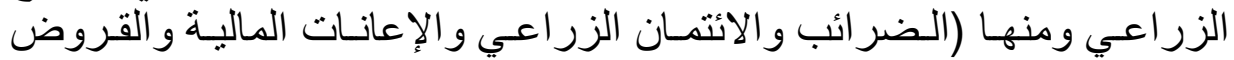

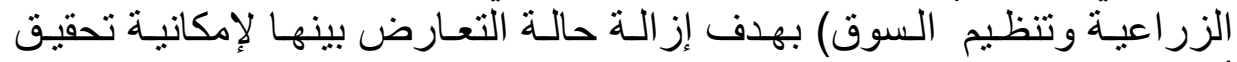

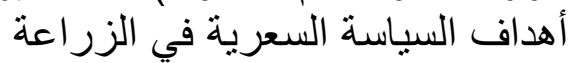

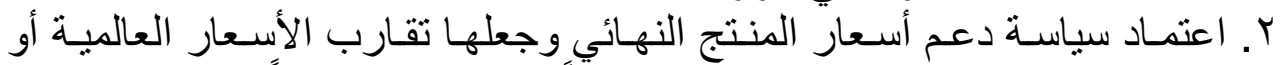

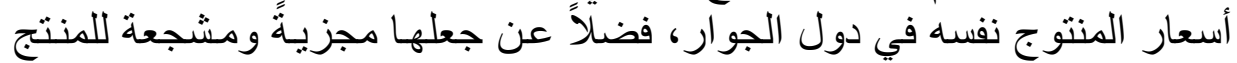
الزراعي بهدف الاستمر ار في الإنتاج وزيادة الكثاف فئافة الإنتاجية.

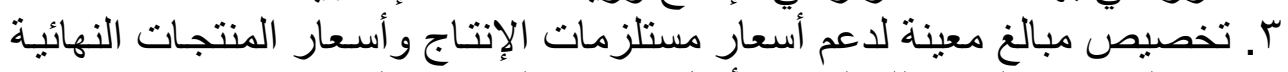

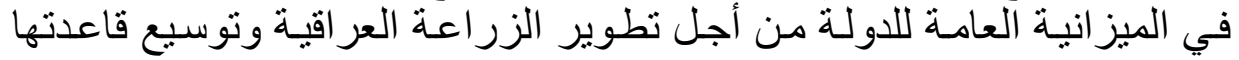

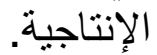

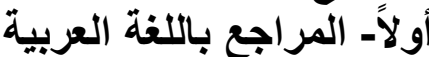
1. أحمد، انتصار محي الداني، .919 1، مسائل في تخطيط سياسة دعم الأسعار في العراق، رسالة

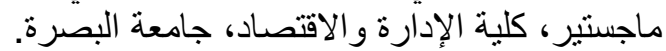

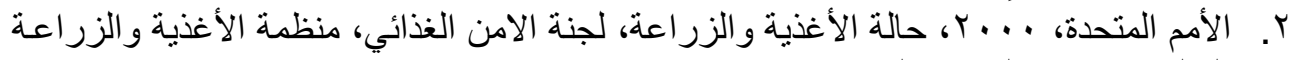

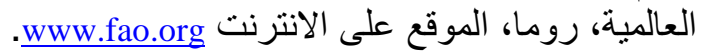

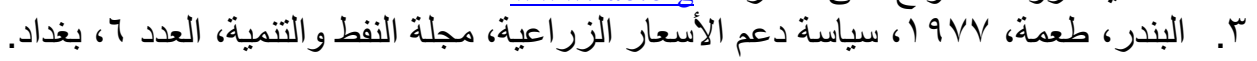

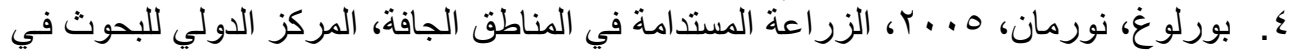

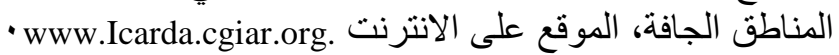




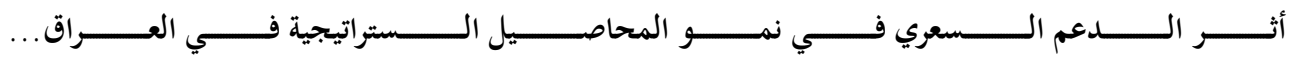

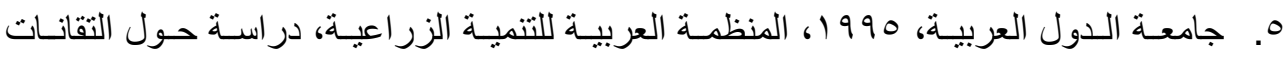

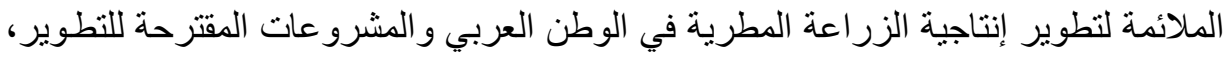

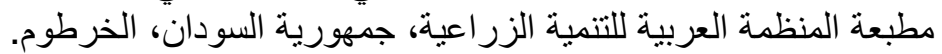

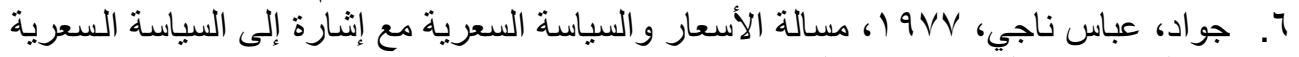

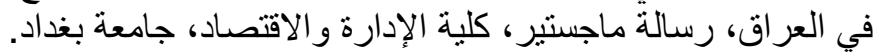

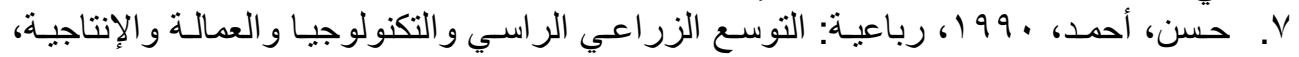

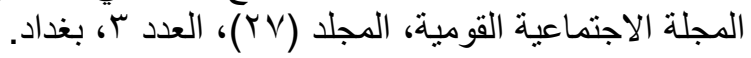

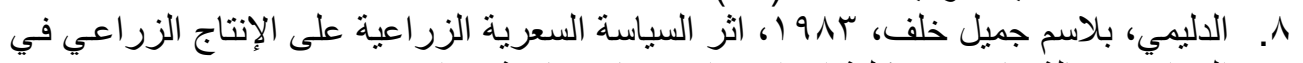

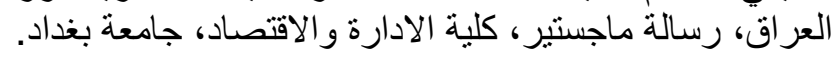

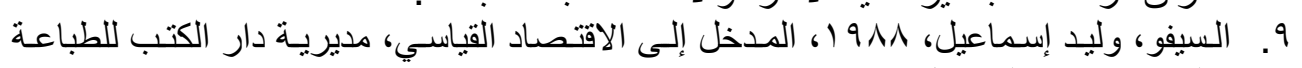

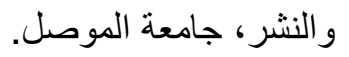

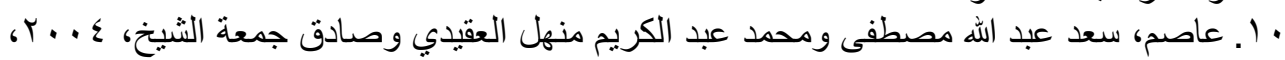

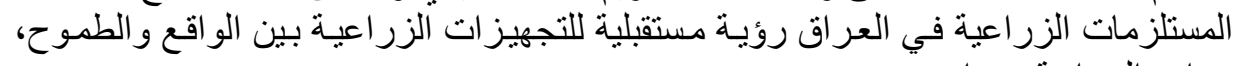

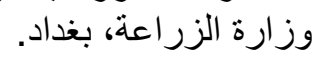

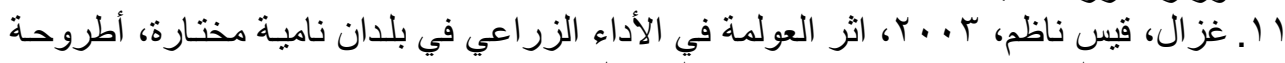

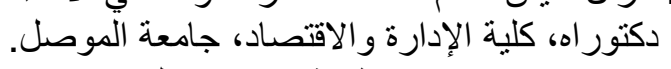

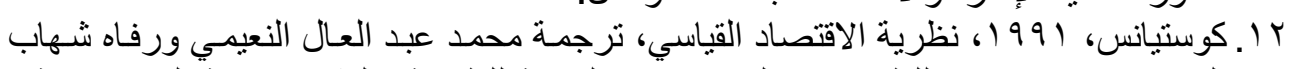

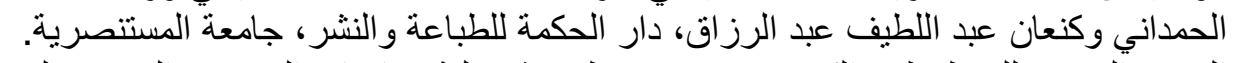

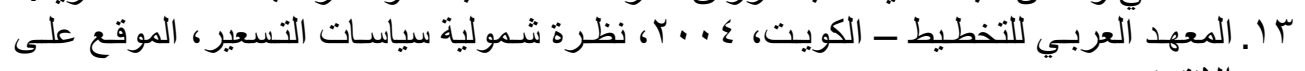

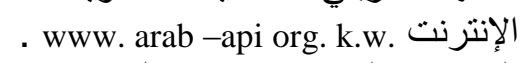

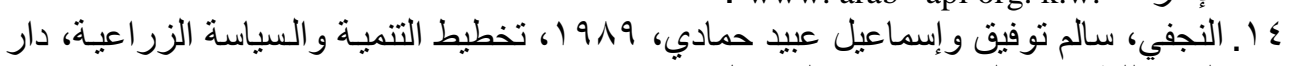

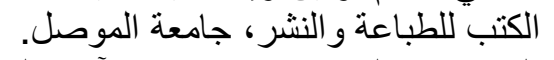

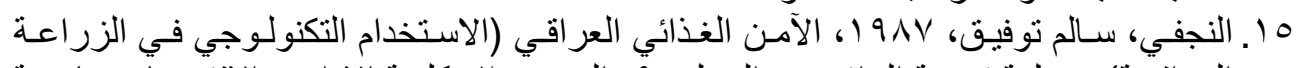

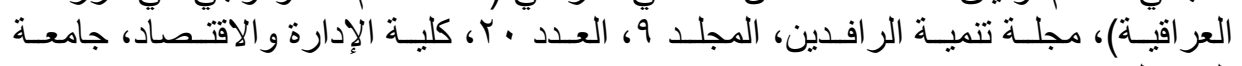

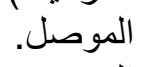

7 ا ـ النجفي، سالم توفيق، r. . . Y، مستقبل الأوضاع الغذائية في العراق (مقاربات في مسالة الدعم

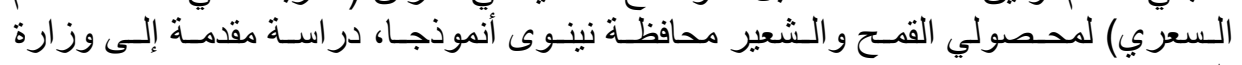
الزر اعة.

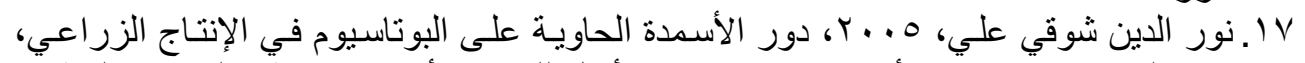

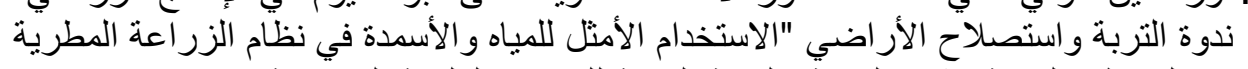

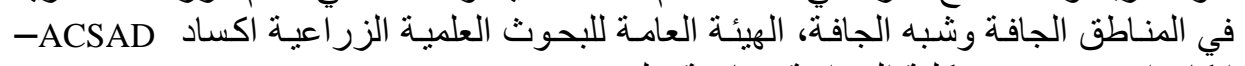

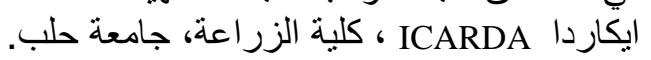

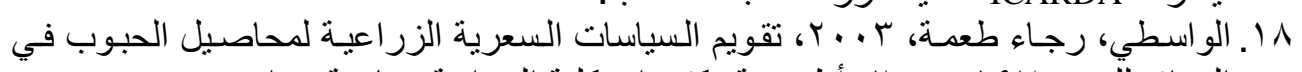

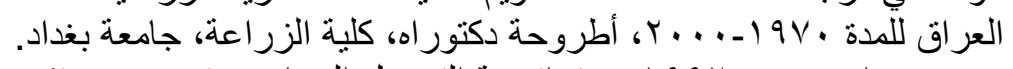

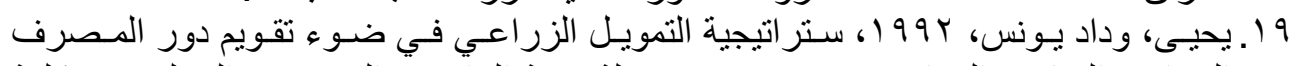

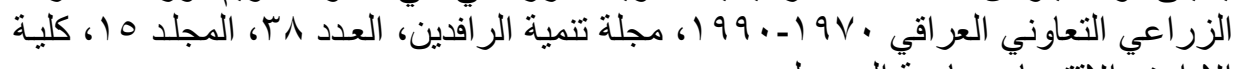

$$
\text { الإدارة والإقتصاد، جامعة الموصل. }
$$

\section{ثانياً المراجع باللغة الأجنبية}

1. C. peter Timmer 1994, Food price \& Agricultural development: The relevance of the Asian experience to Africa, Agriculture vural development, Vol .1, No.1 . 


\section{الدكتور غال وحمد [ـ11]}

2. Kasnakoglu and Curkan 2004, Agricultural Price support in turkey: an Empirical Study, Janarul Journal, www.spring.link.com.

3. Malcolum Gills 1987, Economic of development, Second Edition, W.W, norton and company, New york, London . 